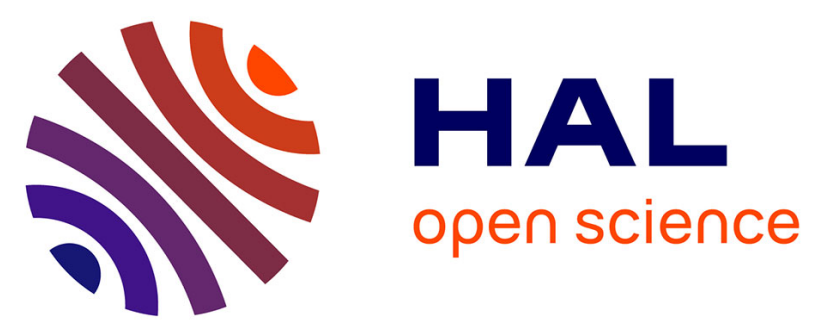

\title{
Genome-wide SNP genotyping of DNA pools identifies untapped landraces and genomic regions that could enrich the maize breeding pool
}

Mariangela Arca, Brigitte Gouesnard, Tristan Mary-Huard, Marie-Christine Le Paslier, Cyril Bauland, Valérie Combes, Delphine Madur, Alain

Charcosset, Stephane Nicolas

\section{To cite this version:}

Mariangela Arca, Brigitte Gouesnard, Tristan Mary-Huard, Marie-Christine Le Paslier, Cyril Bauland, et al.. Genome-wide SNP genotyping of DNA pools identifies untapped landraces and genomic regions that could enrich the maize breeding pool. 2020. hal-02965049

\author{
HAL Id: hal-02965049 \\ https://hal.inrae.fr/hal-02965049
}

Preprint submitted on 12 Oct 2020

HAL is a multi-disciplinary open access archive for the deposit and dissemination of scientific research documents, whether they are published or not. The documents may come from teaching and research institutions in France or abroad, or from public or private research centers.
L'archive ouverte pluridisciplinaire HAL, est destinée au dépôt et à la diffusion de documents scientifiques de niveau recherche, publiés ou non, émanant des établissements d'enseignement et de recherche français ou étrangers, des laboratoires publics ou privés. 
1 Genome-wide SNP genotyping of DNA pools identifies untapped

2 landraces and genomic regions that could enrich the maize

3 breeding pool

4

$5 \quad$ Mariangela Arca ${ }^{1}$, Brigitte Gouesnard ${ }^{2}$, Tristan Mary-Huard ${ }^{1}$, Marie-Christine Le

6 Paslier $^{3}$, Cyril Bauland ${ }^{1}$, Valérie Combes ${ }^{1}$, Delphine Madur ${ }^{1}$, Alain Charcosset $^{1}$, Stéphane D.

$7 \quad$ Nicolas $^{1}$

8 Author's affiliations:

91 Université Paris-Saclay, INRAE, CNRS, AgroParisTech, GQE - Le Moulon, 91190,

10 Gif-sur-Yvette, France

112 Amélioration Génétique et Adaptation des Plantes méditerranéennes et tropicales, Univ

12 Montpellier, CIRAD, INRAE, Institut Agro, F-34090 Montpellier, France

133 Université Paris-Saclay, INRAE, Etude du Polymorphisme des Génomes Végétaux,

1491000, Evry, France

15 Corresponding author: stephane.nicolas@inrae.fr

16 


\section{ABSTRACT}

18 Maize landraces preserved in genebanks have a large genetic diversity that is still

19 poorly characterized and underexploited in modern breeding programs. Here, we genotyped

20 DNA pools from 156 American and European landraces with a 50K SNP Illumina array to

21 study the effect of both human selection and environmental adaptation on the genome-wide

22 diversity of maize landraces. Genomic diversity of landraces varied strongly in different parts

23 of the genome and with geographic origin. We detected selective footprints between landraces

24 of different geographic origin in genes involved in the starch pathway (Sul, Waxyl),

25 flowering time (Zcn8, Vgt3, ZmCCT9) and tolerance to abiotic and biotic stress (ZmASR, NAC

26 and $d k g$ genes). Landrace diversity was compared to that of (i) 327 inbred lines representing

27 American and European diversity ("CK lines) and (ii) 103 new lines derived directly from

28 landraces ("DH-SSD lines"). We observed limited diversity loss or selective sweep between

29 landraces and CK lines, except in peri-centromeric regions. However, analysis of modified

30 Roger's distance between landraces and the CK lines showed that most landraces were not

31 closely related to CK lines. Assignment of CK lines to landraces using supervised analysis

32 showed that only a few landraces, such as Reid's Yellow Dent, Lancaster Surecrop and

33 Lacaune, strongly contributed to modern European and American breeding pools. Haplotype

34 diversity of CK lines was more enriched by DH-SSD lines that derived from the landraces

35 with no related lines and the lowest contribution to CK lines. Our approach opens an avenue

36 for the identification of promising landraces for pre-breeding.

37 Keywords: Zea mays, gene banks, Landraces, Pre-breeding, DNA pooling, Genetic 38 diversity, Selective footprints, Allelotyping 


\section{SIGNIFICANCE STATEMENTS}

41 Maize landraces are a valuable source of genetic diversity for addressing the challenges of 42 climate change and the requirements of low input agriculture as they have been long selected 43 to be well adapted to local agro-climatic conditions and human uses. However, they are 44 underutilized in modern breeding programs because they are poorly characterized, genetically 45 heterogeneous and exhibit poor agronomic performance compared to elite hybrid material. In 46 this study, we developed a high-throughput approach to identify landraces that could 47 potentially enlarge the genetic diversity of modern breeding pools. We genotyped DNA pools 48 from landraces using $50 \mathrm{~K}$ array technology, which is widely used by breeders to characterize 49 the genetic diversity of inbred lines. To identify landraces that could enrich the modern maize 50 germplasm, we estimated their contribution to inbred lines using supervised analysis and a new measurement of genetic distance. 


\section{INTRODUCTION}

Plant genetic resources are the basic raw material for future genetic progress (1-4). Maize landraces are an interesting source of genetic diversity for addressing the challenges of climate change and the requirements of low input agriculture, as they have been long selected to be well adapted to local agro-climatic conditions and human uses (4-7). During the early twentieth century, landraces were used as parent material for the development of improved hybrid varieties to meet the needs of modern agriculture. During this transition from landraces to hybrids, many favorable alleles were probably lost as a result of their association with unfavorable alleles and/or genetic drift (8-11). Nowadays, modern breeding programs tend to focus on breeding populations that can be traced back to a few ancestral inbred lines derived from landraces at the start of the hybrid era (12-15). Landraces that did not contribute to this founding material may be expected to be useful for enriching modern maize diversity, particularly for traits that enhance adaptation to adverse environmental conditions (7). However, maize landraces are used to a very limited extent, if at all, in modern plant breeding programs because they are poorly characterized, genetically heterogeneous and exhibit poor agronomic performance compared to elite hybrid material (3, 6, 16-18). Therefore, understanding the genetic diversity of maize landraces and their relation to the maize elite pool is essential for better management of genetic resources and for genetic improvement through genome-wide association studies, genomic selection and the dissection of quantitative traits $(2,6,7)$.

Maize was domesticated in the highlands of Central Mexico approximately 9,000 years ago $(19,20)$. It then diffused to South and North America $(21,22)$ and spread rapidly out from America (23). It is now cultivated in highly diverse climate zones ranging from $40^{\circ} \mathrm{S}$ to $50^{\circ} \mathrm{N}$. In Europe, the presently accepted hypothesis is that maize was first introduced through Spain by Columbus, although other sources of maize that were pre-adapted to temperate climates have been important for adapting to northern European conditions (22, 24-29). After being introduced in different parts of the world, maize landraces were then selected by farmers to improve their adaptation to specific environments, leading to changes in flowering behavior, yield, nutritive value and resistance to biotic and abiotic stress, resulting in subsequent differentiation of the material $(7,27,30)$.

In recent years, the genetic diversity of maize landraces, which are conserved ex situ, has been studied extensively using various types of molecular markers such as restriction 
86 (SSRs) $(8,23,35,36)$. Single nucleotide polymorphisms (SNPs) are now the marker of choice

87 for various crop species such as maize (37), rice (38) and barley (39). They are the most 88 abundant class of sequence variation in the genome, are co-dominantly inherited, genetically 89 stable, easily automated and, thus, suitable for high-throughput automated analysis (40). 90 Unlike SSRs, allele coding can be easily standardized across laboratories and the cost of 91 genotyping is very low, which is a major advantage for characterizing genetic resources. A 92 maize array with approx. 50,000 SNP markers has been available since 2010 (37). It has been 93 successfully used to analyze the diversity of inbred lines and landraces by genotyping a low 94 number of plants per accession $(13,16,41-44)$.

95 However, due to high within-accession diversity, the characterization of maize landraces 96 should be carried out on a representative set of individuals (45). Despite recent technical 97 advances, genotyping large numbers of individuals remains very expensive in the context of 98 genetic characterization. As a result, DNA pooling (or allelotyping) has been actively 99 developed as a valuable alternative strategy for collecting information on allele frequency 100 from a group of individuals while significantly reducing the effort required for population 101 studies using DNA markers $(46,47)$. In maize, DNA pooling has been successfully used to 102 decipher the global genetic diversity of landraces using RFLP (32) and SSR markers (23, 27, $10328,48,49)$. The recent development of SNP arrays in maize $(37,50)$, combined with DNA 104 pooling, could be useful for characterizing the genetic diversity of maize landraces at a fine 105 genomic scale. In a previous study, we developed a new method for predicting the allelic 106 frequency of each SNP from a maize Illumina 50K array within DNA pools based on the 107 fluorescence intensity of the two alleles at each SNP (51). This new method accurately 108 predicts allelic frequency, safeguards against the false detection of alleles and leads to little 109 ascertainment bias for deciphering global genetic diversity (51).

110 In the present study, we applied this new method on a pilot scale to: i) investigate the 111 genome-wide diversity and genetic structure of 156 maize landraces that are representative of 112 European and American diversity; ii) compare the diversity of these landraces to that of a 113 panel of 327 inbred lines that represent the diversity presently used in North-American and 114 European breeding, the "CK lines" (27) and 103 new inbred lines derived from landraces, the 115 "DH-SSD lines"; and iii) identify the landraces that could potentially broaden the genetic 116 diversity of the CK lines. 


\section{RESULTS}

\section{Genetic diversity within maize landraces}

119 Only 25 SNPs out of 23,412 were monomorphic in the landrace panel. The average total 120 diversity (HT) was $0.338 \pm 0.001$. The distribution of minor allelic frequency (MAF) showed 121 a deficit in rare alleles (MAF<0.05) compared to other frequency classes (Fig. S1).

122 In order to compare the genetic diversity of populations from different regions, we 123 classified the 156 landraces into five geographic groups: Europe (EUR), North America 124 (NAM), Central America and Mexico (CAM), the Caribbean (CAR) and South America 125 (SAM) (Table 1, Fig. S2, Table S1). All five geographic groups displayed both alleles for 126 nearly all loci, with the exception of CAR which was monomorphic at 1,227 loci out of 127 23,387 (Fig. S3). The lowest and highest within-group HT was found in CAR (0.301) and 128 CAM (0.328), respectively. Note that there was an excess of rare alleles in EUR, CAR and NAM but not in SAM and CAM (Fig. S1).

130 The average number of alleles per locus and per landrace within the entire landrace panel 131 was $1.629 \pm 0.003$ and ranged from 1.098 (Ger8) to 1.882 (Sp11). Gene diversity within 132 landraces (Hs) was on average $0.192 \pm 0.001$, (Table 1) and varied between 0.03 (Ger8 and 133 Ger9) and 0.28 (Sp11) (Table S1). The CAM group displayed on average the highest diversity $134(0.219 \pm 0.008)$, while the EUR group displayed the lowest $(0.177 \pm 0.002)$.

135 Genetic differentiation between landraces (FST) was 0.428 on average. FST within a 136 geographic group varied between 0.314 (CAR) and 0.434 (EUR) (Table 1). Overall genetic 137 differentiation between geographic groups was low (FST=0.05). FST between pairs of 138 geographic groups varied between 0.016 (EUR and NAM) and 0.083 (NAM and CAR) (Table 139 S2).

140 Relationship between maize landraces and population structure

141 The average modified Roger's distance (MRD) between landraces was 0.379. The lowest 142 MRD between landraces was 0.158 (Chi12 and Chi9). It is slightly higher than the distance 143 between two pools of independent individuals from a same population (0.092-0.120, (51)). 144 The highest MRD was 0.552 (Ant1 and Ger8). The average MRD between populations from a 145 same geographic group ranged from 0.320 (CAR) to 0.367 (EUR) (Table 1). The average 146 MRD between populations belonging to two different geographic groups varied between 1470.354 (CAM vs CAR) and 0.420 (NAM vs CAR) (Table S2). 
We investigated the relationship between maize landraces using Principal Coordinate Analysis (PcoA) and Ward hierarchical clustering based on MRD (Fig. 1). For both PcoA and

150 Ward hierarchical clustering analysis, landraces mostly clustered according to their 151 geographic proximity (Fig. 1, Fig. S4, Fig. S5). The first axis (PC1, 18.4\% of the total 152 variation) discriminated (i) temperate landraces belonging to the Northern Flint cluster (from 153 northern Europe and North America) from (ii) tropical and subtropical landraces (from the 154 Caribbean and South and Central America) (Fig. 1A). The second axis (PC2, 5\% of the total 155 variation) discriminated (i) North American (Corn Belt Dent cluster), Central American and 156 Mexican populations (Mexican cluster) from (ii) Italian (Italian Flint cluster), and Spanish and 157 French populations (Pyrenean-Galician cluster). Ward hierarchical clustering showed that at 158 the highest level (k=2, Fig. 1B), 62 of the 83 European landraces clustered together (European 159 cluster) while 70 of the 83 American landraces clustered together (American cluster). At a 160 deeper level $(\mathrm{k}=7)$, we distinguished 4 clusters of American or European landraces, each 161 originating from a geographic area with homogeneous agro-climatic conditions (cluster a, b, e 162 and f in Fig. 1B, Fig. S4). Cluster "a" grouped 15 landraces that originated mainly in Mexico 163 and southwestern USA. Cluster "b" comprised 10 South American landraces that originated 164 along the Andean Mountains. Cluster "e" grouped 31 European landraces that originated 165 either along the Pyrenean Mountains or in Central Eastern Europe. Cluster " $\mathrm{f}$ " grouped 166 mainly Italian Flint landraces. Three clusters grouped together American and European 167 landraces (cluster c, d and g on Fig. S4). Cluster "c" comprised 14 dent landraces that originated mainly from Eastern European landraces and the US Corn Belt. Cluster "d" grouped 65 landraces mostly from southern Spain (latitude $<40^{\circ} \mathrm{N}$ ), southwestern France and 170 from the Caribbean Islands and countries bordering the Caribbean Sea (d1, d2 and d3 on Fig. 171 S4). Cluster "g" comprised 12 North American flint landraces from higher latitudes $\left(>40^{\circ} \mathrm{N}\right)$ 172 and 18 northeastern European landraces mainly from Germany (g on Fig. S4). Using a 173 pairwise Mantel test for each geographic area, we observed a low but significant correlation 174 between the genetic distance and geographic distance matrices for EUR $\left(\mathrm{r}^{2}=0.05, \mathrm{P}<0.001\right.$, 175 Fig. S6A), NAM $\left(\mathrm{r}^{2}=0.12, \mathrm{P}<0.001\right.$, Fig. S6B $)$ and CAM $(\mathrm{r} 2=0.0858, \mathrm{P}=0.02$, Fig. S6C).

176 We analyzed the genetic structure of 156 landraces using the ADMIXTURE program. 177 Likelihood analysis indicated that the optimal number of genetic groupe was $\mathrm{K}=2, \mathrm{~K}=3$ and $178 \mathrm{~K}=7$ (Fig. S7). We considered $\mathrm{K}=7$ as the reference, as this value was consistent with the one 179 obtained with 24 SSRs by Camus- Kulandaivelu et al. (27). Landraces from different 180 geographic regions were assigned to different genetic groups, with a clear trend along latitude 
181 and longitude. Fig. 2). Assignment to these groups was also highly consistent with PcoA and 182 hierarchical clustering (Fig. 1, Fig. 2, Fig. S4, Fig. S5). The genetic structure obtained with 183 SNP markers was highly consistent with that obtained with the 17 SSR markers; indeed, $72 \%$ $184(\mathrm{~K}=7)$ to $100 \%(\mathrm{~K}=3)$ of landraces were assigned to the same group by both types of markers 185 (Table S3). The main differences between the SSR and SNP results at $\mathrm{K}=7$ were that the 186 Northern Flint landrace group obtained with SNPs is split in two with SSRs and the separate 187 Pyrenean-Galician and Italian groups found with SNPs form a single group with SSRs.

\section{Scanning the maize landrace genomes for regions under selection}

189 Using a sliding window approach, we identified 14 regions with windows containing at least two SNPs with extremely low genetic diversity $\left(\overline{\mathrm{HT}_{1}}<0.069\right)$ across the entire landrace panel (Fig. 3A, Table S4). These regions were mainly located in the centromeric region of

192 chromosomes 5 and 7. Genomic regions showing low diversity within geographic groups 193 were most abundant in CAR (67), followed by EUR (56), CAM (39), SAM (36) and NAM 194 (26) (Fig. 3E to3I, Table S4). These regions were mostly located close to the centromeres but 195 varied between geographic groups. In the centromeric region of chromosome 1, we observed 196 (i) no loss of diversity for CAR and NAM and (ii) a depletion in genetic diversity for CAM, 197 EUR and SAM. Conversely, we observed a strong depletion on chromosomes 3 and 4 in CAR landraces that was not observed in other geographic groups.

Outlier analysis of FST values among individual landraces identified 20 and 17 genomic regions displaying high differentiation $\left(\overline{\mathrm{FST}_{1}}>0.568\right)$ and low differentiation $\left(\overline{\mathrm{FST}_{1}}<0.235\right)$ between landraces, respectively (Fig. 3L, Table S4). Genetic differentiation was highest upstream of chromosome 6 (Sp10 in Table S5), in two regions upstream of chromosome 4 (Sp6 and Sp7in Table 2) and in one region on chromosome 3 (Sp3 in Table 2).

Outlier FST analysis between geographic groups identified 26 regions with high differentiation $\left(\overline{\mathrm{FST}_{\mathrm{g}}}>0.150\right)$ and 8 regions with low differentiation $\left(\overline{\mathrm{FST}_{\mathrm{g}}}<0.007\right)$ (Fig. 3J, Table S4); BAYESCAN identified 379 loci under divergent selection (Fig. 3J, Table S6 and S7, Fig. S8). The five genomic regions that were previously identified as being highly differentiated between landraces by outlier FST analysis were also detected by both FST outlier and BAYESCAN analyses between geographic groups. (Table 2). Only one highly

210 differentiated genomic region was identified between landraces but not between all five 211 geographic groups (Sp10 in Table S5) whereas 6 genomic regions were identified exclusively 212 between the five geographic groups ( $\mathrm{Sg} 6,7,13,15,17,18$ and 20 in Table S5). These regions 
213 displayed contrasted allelic patterns across geographic groups. Sp10 (11.7 Mbp - 15.3 Mbp

214 on chromosome $6, \overline{\mathrm{FST}_{\mathrm{g}}}=0.08$ and $\overline{\mathrm{FST}_{1}}=0.65$ ) had 9 SNPs that were close to fixation in

215 CAM $(\mathrm{HT}<0.1)$, but were segregating in NAM $(\sim 0.4)$ and also to a lesser extent in EUR,

$216 \mathrm{CAR}$ and SAM (HT 0.2). Sg2-Sp3 (84-85 Mbp on chromosome 3, $\overline{\mathrm{FST}_{\mathrm{g}}}=0.18$ and $\overline{\mathrm{FST}_{\mathrm{l}}}=$

217 0.63) had 3 SNPs showing a continuous allelic frequency gradient between tropical and

218 temperate landraces with one allele largely predominant in NAM and EU ( 70\%), minor in

219 CAM ( 30\%) and absent in CAR ( 0\%). Sg4-Sp6 (40.3-41.8Mbp on chromosome 4, $\overline{\text { FST }_{\mathrm{g}}}=$

2200.27 and $\overline{\mathrm{FST}_{1}}=0.63$ ) had 4 SNPs that were nearly fixed in temperate landraces (NAM, EUR)

221 and displaying intermediate frequencies in CAM. By contrast, the Sg5-Sp7 region

$222\left(\overline{\mathrm{FST}_{\mathrm{g}}}=0.16, \overline{\mathrm{FST}_{\mathrm{l}}}=0.63\right)$ displayed higher diversity in temperate $\left(\mathrm{HT}_{\mathrm{NAM}}\right.$ and $\left.\mathrm{HT}_{\mathrm{EUR}} \sim 0.4\right)$

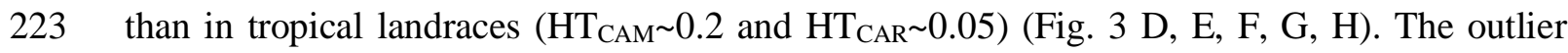

224 loci displaying the highest FST values within this region were located up to $10 \mathrm{kbp}$ upstream

225 of the $S u l$ gene which is involved in the starch pathway.

226 Outlier FST analysis between pairs of geographic groups identified 214 and 41 regions 227 displaying high and low differentiation, respectively (Fig. S9). BAYESCAN analysis

228 identified 363 SNPs under selection between pair of geographic groups, including 167 new

229 SNPs that were not previously identified between all five geographic groups (Table S8). The

230 new highly differentiated regions identified by BAYESCAN were mostly specific to a single

231 pair of geographic groups (Fig. S9, Fig. S10). Putative functions could be assigned to 272 of

232 the $536(50.7 \%)$ outlier loci identified by BAYESCAN analysis of all five and pairs of

233 geographic groups. These included known genes involved in adaptation to abiotic stress,

234 flowering time or human uses (Table S8 and S9).

235 Genome-wide comparison of diversity between landraces and inbred 236 lines

237 The panel of CK lines contained more monomorphic SNPs than landraces (263 vs 25) but 238 still captured $99 \%$ of the alleles present within the landrace panel. HT was slightly higher in 239 inbred lines than in landraces $(0.353$ vs 0.338). Allelic frequency of loci and HT values in 240 inbred lines and landraces were strongly correlated $\left(r^{2}=0.89\right.$ and $r 2=0.80$, respectively, Fig.

241 S11). Overall genetic differentiation between landraces and inbred lines was limited (0.010 \pm 242 0.066). Some regions were more diverse in landraces than in inbred lines, notably the peri243 centromeric region of chromosomes 3 and 7, while the opposite was found in centromeric 244 regions of chromosomes 1, 3, 4, 5 and 6 (Fig. 3B). 
Comparison of landraces and inbred lines using the outlier FST approach identified 128 highly differentiated genomic regions (FST> 0.04) and 32 regions with an excess of similarity

247 (FST <4.21e-05). While highly differentiated regions were mainly located on chromosomes 3,

$2484,8,9$ and 10, weakly differentiated regions were mainly located on chromosomes 3, 5 and 9

249 (Fig. 3K). BAYESCAN analysis of landraces $v s$ inbred lines identified 61 loci $(0.3 \%)$ that

250 were significantly more differentiated than expected under the drift model (Fig. 3K, Table $251 \mathrm{~S} 10)$.

252

253

254

255

256

257

258

259

260

261

262

263

264

265

266

267

268

269

270

271

272

273

274

275

276

Relationship between inbred lines and landrace populations: genetic distances and supervised analysis

The average MRD between landraces and CK lines was $0.499( \pm 0.034)$, which is greater than between landraces $(0.379 \pm 0.059)$ and less than between lines $(0.590 \pm 0.024)$. The distribution of MRD genetic distances between a given landrace and CK lines (MRD $\mathrm{LI}_{\text {) }}$ is displayed as a series of boxplots (Fig. 4A) listed in ascending order of landrace expected heterozygosity (Hs) (Fig. 4B). Landraces with a low genetic diversity generally showed a higher median and a wider range for $\mathrm{MRD}_{\mathrm{LI}}$, with some notable exceptions (e.g. Chi5, Per10, Par2, Par1, Bra4, Ecu17, Vir4 and Svt1 in Fig. 4). Accordingly, the median $\mathrm{MRD}_{\mathrm{LI}}$ and the within landrace genetic diversity Hs were strongly negatively correlated $(r=-0.978, t=-$ 61.314, p-value < 2.2e-16) and displayed a linear relationship (Fig. S12). Considering a similar level of genetic diversity, some landraces were closely related to certain inbred lines, whereas other landraces were not (Fig. 4A and Fig. S12).

In order to identify the source material of modern varieties, and a contrario the landraces that did not contribute much to these varieties, we quantitatively assigned 442 inbred lines to 166 landraces using a supervised analysis (Table S11). The 234 first cycle inbred lines (i.e. directly derived from a single landrace) were assigned to a total of 60 landraces. Among these landraces, 47 had at least one inbred line assigned with a probability $>60 \%$. For first cycle inbred lines of known pedigree and whose ancestral landrace is included in our study (a total of 121 lines and 50 landraces), we noted a very good match between pedigree and main assignment (71.9\% of cases). Among these 121 lines, DH-SSD lines, which were derived recently from landraces, were more frequently assigned to their population of origin than lines from the diversity panel (77.6\% vs 58.3\%, p-value=0.04). For the 208 inbred lines from more advanced breeding cycles, we identified a total of 66 landraces as the main assignment of at least one inbred line. Among these, temperate inbred lines were frequently assigned to Reid's 
277 Yellow Dent and Lancaster Surecrop. Chandelle (one of the few tropical landraces in our 278 study) was identified as the most likely source for many tropical lines.

279 A few landraces contributed strongly to the whole diversity panel, with the 10 first 280 landraces cumulating half of the total contributions (Fig. 4C, Fig. S13A). 80\% of lines were 281 assigned to these 10 landraces with a $>60 \%$ probability (Fig. S13B). Interestingly, the mean 282 contribution of landraces differed strongly between first cycle lines and more advanced lines 283 with a strong decrease $(>1 \%)$ for 15 landraces and a strong increase $(>1 \%)$ for 8 landraces 284 (Fig. S13C).

285 We tested whether the mean contribution of landraces and the MRD $\mathrm{LI}_{\text {distance }}$ 286 "normalized" by within landraces genetic diversity could be used as a criterion to identify 287 untapped sources of genetic diversity that could enrich the CK line panel. First, we selected $28866 \mathrm{DH}-\mathrm{SSD}$ lines that were correctly assigned to 33 landraces from the landrace panel. We 289 then classified these 33 landraces according to: (i) their average contribution to CK lines (Fig. 290 5A) and (ii) the normalized MRD distance from their closest lines (Fig. 5C). For each class, 291 we estimated with 979 haplotype markers the average number of new haplotypes discovered 292 in the 66 DH-SSD lines compared to those existing in the CK lines. We discovered 66 new 293 haplotypes in the DH-SSD lines compared to 4,355 different haplotypes in the CK lines. The 294 number of new haplotypes discovered in DH-SSD lines ranged from 0 (Bul3) to 11 (Arg8). 295 The average number of new haplotypes was significantly higher for lines derived from 296 landraces with a low contribution than those with a high contribution (p-value $=0.008$, Fig. 297 5B). It was also higher for landraces that were not close to any of the CK lines than for those 298 that were close to certain lines (p-value $=0.0004$, Fig. 5D). 


\section{DISCUSSION}

300

301

302

303

304

305

306

307

308

309

310

311

312

313

314

315

316

317

318

319

320

321

322

323

324

325

326

327

328

329

\section{Patterns of genetic diversity and population structure within landraces}

The total expected heterozygosity observed in our study based on SNPs (0.338) was lower than the values reported previously for landraces of comparable origin that were analyzed with SSR markers (0.58 in (26), 0.63 in (27), 0.62 in (28)) but comparable to those observed with SNPs in diversity inbred line panels $(42,43)$. These differences can be primarily explained by the fact that SNP markers are typically bi-allelic, whereas SSR markers are multi-allelic, which has the potential to increase gene diversity $(43,52)$. Trends in the partition of genetic diversity within and between landraces, and within and between geographic groups were similar to previous findings. The diversity of individual landraces represented on average $57 \%$ of the total genetic diversity, which was slightly lower than for RFLP markers $(\sim 66 \%$ in $(23,26))$. This difference may be due to the counter-selection of SNP markers with low MAF during the design of 50K Illumina array (37), which may increase total diversity more than within diversity $(53,54)$. On the other hand, genetic structure analyses based on SNPs and 17 SSRs were highly congruent, which indicates that the ascertainment bias of prefixed PZE SNPs from the 50K Illumina chip used to study landraces is negligible $(43,51)$.

Each geographic group contained most of the overall landrace genetic diversity, ranging from 89\% (CAR) to 97\% (CAM). Central American and Mexican landraces displayed the highest diversity, which is consistent with their proximity to the center of maize domestication $(13,20)$. This confirms that genetic diversity was lost during the spread of maize away from its domestication center due to successive bottlenecks related to climatic adaptation and isolation by distance $(7,21,22,29,55)$. This loss of genetic diversity is consistent with the scenario of maize diffusion with (i) less genetic diversity in European than in North and South American landraces, and (ii) more diversity in South America than in North America, where maize was introduced more recently $(21,23,29,35)$. Our results nevertheless confirm that the bottleneck during the introduction of maize in Europe was certainly limited, as also shown by Brandebourg et al., (29) with whole genome sequencing of 67 inbred lines from Europe and America. Some northern European landraces originating from Germany and Austria have extremely low genetic diversity ( $\mathrm{Hs}<0.10)$, with more than $70 \%$ of loci being fixed, suggesting a strong bottleneck. The fact that some of these landraces 
330 have been cultivated mostly in gardens may have decreased their effective population size

331 (26). The genetic load could have been more or less purged depending on the severity and the

332 duration of the bottleneck. This could explain the strong variation in success rate observed for

333 deriving inbred lines from European Flint landraces by haplodiploidization $(56,57)$.

334 Genetic distance, Ward hierarchical clustering (Fig. 1B), principal component (Fig. 1A) 335 and population structure (Fig. 2) analyses showed major trends in population structure. We 336 confirmed the central position of Mexican and Caribbean landraces and a clear differentiation 337 between North and South American landraces (Fig. 1 and 2). This is consistent with the 338 domestication of maize in Mexico followed by southwards and northwards dispersion (22, 339 55). The similarity between landraces from southern Spain and the Caribbean confirms the 340 historical data on the introduction of maize in the south of Spain by Columbus in 1493 after 341 his first trip to the Caribbean (Fig. 1B, cluster d). Strong similarities between groups of 342 northeastern American and northeastern European landraces (mostly from Germany, Poland 343 and Austria) (Fig. 1B, cluster g) also supports an independent introduction of North American 344 material that was pre-adapted to the northern European climate (21, 22, 26, 28, 29, 58). Some 345 landraces from northern Spain and southwestern France, located along the Pyrenean 346 Mountains, were admixed either with Caribbean or Northern Flint. This result supports the 347 hypothesis that new Pyrenean-Galicia Flint groups originated from hybridization between 348 Caribbean and Northern Flint material that were introduced in southern Spain and northern 349 Europe, respectively. (27, 29, 59). Interestingly, some southwestern Spanish landraces have 350 elevated admixture with Italian Flint groups and are closely related to Italian landraces on the 351 NJ tree (Fig. S5), while northern Spanish landraces (latitude $>42^{\circ} \mathrm{N}$ ) do not. These results 352 support the hypothesis that Italian landraces are probably derived from an ancestor from 353 southern Spain $(29,60)$. Our results also highlighted a new putative hybridization event in 354 Central Eastern Europe. Central Eastern European landraces were close to Italian Flint 355 landraces on the Ward cluster tree and one northern Italian Flint landrace (Nostrano 356 Quarantino) was admixed with Italian Flint ( 30-40\%) and Northern Flint ( 30-50\%). This 357 suggests that Italian Flint landraces certainly spread in Central Eastern Europe, where they 358 intermated with Northern Flint landraces.

359 Differentiation of landraces was greater in Europe than in Central America and the 360 Caribbean, indicating that gene flow is lower in the latter two. Genetic and geographic 361 distances were significantly correlated in NAM, EUR and CAM but not in SAM and CAR 362 (Fig. S6), suggesting that isolation by distance played a role in shaping the genetic structure of 
363 maize landraces in these regions, albeit to a variable degree. In the case of CAM, the effect of

364 isolation by distance is partially blurred by variation in altitude producing major gradients in 365 environmental conditions (temperature, rainfall) (7, 30, 61). Indeed, Mexican landraces 366 clustered according to both altitude and distance (Fig. 1B, Table S1) suggesting 367 environmental adaptation $(7,30)$.

\section{Genomic pattern of nucleotide variation in landraces}

369 FST outlier and BAYESCAN analyses identified 13 genomic regions that showed high 370 levels of differentiation between geographic groups and/or landraces (Table S5). The four

371 highly differentiated genomic regions between landraces displayed contrasted patterns of 372 allelic frequencies between geographic groups (Table 2, Table S5), suggesting different types 373 of selection. The Sp10 region was found to be highly differentiated between landraces but not 374 between the five geographical groups. It suggests that there was strong selection in some 375 specific geographic areas but not across all geographic groups. This region contains genes associated with tolerance to high temperature and evaporative demand (62). The second genomic region (Sg4-Sp6: 7.8 Mbp - 9.3 Mbp on chromosome 4) was nearly fixed in temperate landraces (NAM, EUR) whereas it showed intermediate frequencies in CAM, suggesting a strong directional selection effect during the spread from Mexico to North America. This results is in agreement with Romero-Navaro et al. (55), who identified 5 SNPs in this region with allelic frequencies varying significantly with latitude in American landraces, and Brandeburg et al., (29), who identified two highly differentiated regions between Corn Belt Dent and Tropical first cycle lines. By contrast, the third genomic region (Sp5-Sg7; 40-41.9 Mbp on chromosome 4) displayed higher genetic diversity in temperate landraces (NAM, EUR) than in tropical landraces (CAM, CAR) suggesting strong diversifying selection in EU and NAM. This region included the Sul gene, which is involved in the starch pathway and is known to be under strong selective pressure (63-66). RomeroNavaro et al., (55) also found an association between allelic frequency variation at the Sul locus and both latitude and longitude. Futhermore, Brandeburg et al., (29) identified a strong selective sweep between Corn Belt Dent/Tropical and Northern Flint first cycle lines in the Sul gene. The fourth region ( $\mathrm{Sg} 2-\mathrm{Sp} 3 ; 84-85 \mathrm{Mbp}$ on chromosome 3) showed a continuous gradient of allelic frequencies between tropical and temperate landraces suggesting strong directional selection for adaptation either to temperate or tropical climates. In agreement with

394 this finding, Romero-Navaro et al., (55) identified in this region 22 and 4 SNPs with allelic 
395 frequencies varying significantly with altitude and latitude, respectively. This region also

396 carries a large $6 \mathrm{Mbp}$ inversion that is putatively involved in flowering time variation (55).

397 BAYESCAN analysis between geographic groups identified several regions that were not 398 identified by outlier FST analysis (Table S8 and S9). Notably, we identified several loci under 399 strong selection that were close to genes known to be involved in flowering time variation: (i) 400 PZE-108070380 on chromosome 8 (123.5 Mbp) localized 5 kbp upstream of Zcn8 (42, 67, 401 68); (ii) PZE-109070904 on chromosome 9 (115.7 Mbp) in ZmCCT9 (69); (iii) two loci on 402 chromosome 3 (PZE-103098664 (158.9 Mbp) and PZE-103098863 (159.17 Mbp) close to $403 \mathrm{Vgt3}$, a major loci that is strongly associated with flowering time variation in temperate maize $404(62,70)$. We also identified several genes/genomic regions that are putatively involved in 405 adaptation to abiotic stress: (i) PZE-102108435 on chromosome 10 that is $10 \mathrm{kbp}$ upstream of 406 ZmASR2 which is involved in abscisic stress ripening (71); (ii) PZE-104128228 on 407 chromosome 4 in the nactf125 gene (within Sg6 in table S5), PZE-102051809 in the nactf36 408 gene (chromosome 1) and PZE-107058109 in the nactf14 gene (chromosome 7), all of which 409 belong to the NAC protein family, which encodes plant transcription factors involved in biotic 410 and abiotic stress responses (72); (iii) two diaglycerol kinases ( $d g k 2$ and $d g k 3$ ) that exhibit 411 differential expression patterns in response to abiotic stress including cold, salinity and 412 drought and are upregulated in cold conditions (73). Finally, we identified several genomic 413 regions carrying genes involved in the hormonal systems regulating growth, cell division and 414 proliferation such as giberellin2-oxydase9 (ZmGA2ox9, GRMZM2G152354), phytosulfakine 415 (GRMZM2G031317) or in the starch pathway (Sul, waxyl, dull endosperm1).

416 The detection of genomic regions and loci under selection have therefore allowed the 417 identification of genes that underlie the adaption of maize to diverse agro-climatic conditions 418 and/or human uses during the spread of landraces from America (7, 22, 23, 29, 55, 74). These 419 genomic regions could be useful for mining new alleles from landraces, retrieving some of the 420 genetic diversity that was lost by genetic drag linked to genes close to those under selection $421(7,41,74)$, or creating new genetic diversity by targeted mutation (7). pool

424 Intensive selection to enhance agronomic performance can considerably reduce genetic diversity in crops (1). However, we found little difference in genetic diversity between 426 landraces and inbred lines, which is consistent with the low genetic differentiation we 
427 observed between landraces and inbred lines. This suggests that the genomic diversity 428 (inferred from SNPs) present in landraces was retained in our panel of CK lines and that 429 selection during maize improvement has not altered allele diversity over a very broad 430 geographic scale. This observation is similar to findings in soybean (75) and wheat (76), 431 which also showed a minor effect of crop improvement on diversity, suggesting that landraces 432 have been and still are extensively used in the development of modern inbred lines in these 433 crops. It is important to note however that our line panel included many old lines that have 434 made only a limited contribution, if any, to commercial F1 hybrids or recent breeding pools. 435 Our panel therefore certainly overestimates the genetic diversity present in the germplasm of 436 modern breeding inbred lines (57).

437 Several factors could be responsible for the low genetic erosion accompanying the 438 transition from landraces to inbred lines. A first hypothesis is that selection during modern 439 maize breeding targeted only a small number of genes (77) and therefore affected genetic 440 diversity and allelic frequency only in the genomic regions flanking the genes under selection. 441 Another hypothesis is that, even if only a limited number of landraces were used as parents of 442 first cycle lines, i.e. the initial modern inbred line breeding pools, selection of genetically 443 diverse and complementary heterotic groups may have mitigated the loss of diversity (78). 444 Furthermore, SNPs from 50K arrays were previously identified in 27 lines (79). These SNPs 445 may not reflect well the total genetic diversity of landraces, as certain specific landrace 446 haplotypes may not have been transmitted to first cycle lines due to their deleterious effect at 447 the homozygous state (inbreeding depression) or gamete sampling (drift) (57).

448 Despite the limited differences in overall diversity between landraces and inbred lines, two different approaches highlighted that the majority of landraces had made a limited contribution to recent breeding. We identified a number of landraces with a high median Hs value and a small $\mathrm{MRD}_{\mathrm{LI}}$ distance range reflecting a lack of similarity similarity to any inbred 452 line. These landraces probably did not contribute to the modern maize germplasm. Indeed, 453 supervised analysis showed that inbred lines from our diversity panel could be traced back to 454 a few landraces and that the first 10 landraces cumulated half of the total contribution to the 455 diversity panel. Most of these landraces (Reid's Yellow Dent, Lancaster Surecrop and Krug 456 Yellow Dent for the dent genetic group, Lacaune and Gaspe Flint for the flint genetic group 457 and Chandelle for Tropical lines) were previously identified as the source of the modern 458 maize breeding germplasm $(12,13,55)$. Interestingly, we observed a large increase or 459 decrease in the contribution of landraces between first cycle lines and more advanced lines 
460 (Fig. S13C). This can be explained by the fact that some lines were extensively used to derive 461 more advanced lines whereas others were not $(12,14,15)$. Interestingly, DH-SSD lines that 462 were recently derived from landraces were assigned more frequently (and with higher 463 probability) to their population of origin than older lines that were maintained for a long time 464 in gene banks. This suggests that some landraces could have evolved since contributing to 465 inbred lines from the diversity panel or that the pedigree of these lines was erroneous. Our 466 results suggest that we could use supervised analyses to curate the landrace collection and the 467 pedigree of first cycle lines.

468 In order to identify landraces that differ the most from inbred lines, we developed an 469 indicator of genetic distance from inbred lines which was normalized by their genetic 470 diversity (Fig. S12). By classifying landraces according to (i) this normalized distance and (ii) 471 their average contribution to reference inbred lines, we were able to identify landraces that 472 have the greatest potential to broaden the genetic diversity of these lines (Fig.5). By 473 combining closely located SNPs, we were able to identify novel haplotypes in the DH-SSD 474 lines, which were absent in the $\mathrm{CK}$ panel, even though both alleles were present in landraces 475 and the inbred line panel. The number of new haplotypes was significantly higher for DH476 SSD lines created from landraces classified as genetically distant from the modern germplasm 477 according to the criteria described previously, which confirms their relevance when choosing 478 landraces for diversity enhancement. This strategy to identify untapped landraces in modern 479 breeding germplasm can be easily extended to other plant species, other material (hybrids, 480 private germplasm), and other technologies (sequencing). Additionally, this strategy can be focused on some genomic region to identify new alleles of interest. Our strategy opens an avenue to identify valuable landraces and genomic regions for prebreeding.

\section{MATERIALS AND METHODS}

\section{Plant material}

\section{Landraces}

A total of 156 different landrace populations (Table S1) were sampled from a panel of 413 landraces (Supplementary Information 1). These 156 landraces captured a large proportion of European and American diversity and have been analyzed in previous studies using RFLP $(25,31-34)$ and SSR markers $(23,27,28)$. Each population was represented by either one or 
490

491

492

493

494

495

496

497

498

499

500

501

502

503

504

505

506

507

508

509

510

511

512

513

514

515

516

517

518

519

two sets of 15 individual plants (for 146 and 10 populations, respectively), pooled equally as described in Reif et al. (48) and Dubreuil et al. (28). The 166 DNA samples corresponding to the 156 landrace accessions were classified into five geographic groups (Table S1): Europe (EUR), North America (NAM), Central America and Mexico (CAM), the Caribbean (CAR) and South America (SAM).

\section{Inbred lines}

We analyzed 234 inbred lines that were derived directly by single seed descent or by haplodiploidization of landraces, referred to as "first cycle lines", and 208 lines that were derived from a more advanced cycle of breeding, referred to as "advanced lines" (Table S11). These 442 lines were partitioned into three sets (the "Panel" column in Table S11):

1. "CK lines": a panel of 120 first cycle and 207 advanced lines (327 lines in total) representing American and European diversity $(27,42)$ including some key founders of modern breeding programs (e.g. F2, B73, C103).

2. "Parent Controlled Pools": a set of 12 lines used to build 4 series of 8 controlled DNA pools (see below).

3. "DH-SSD lines": a set of 45 single seed descent (SSD) and 58 double haploid (DH) lines derived recently from 48 landraces (first cycle lines).

\section{Controlled DNA Pools}

To prepare the controlled DNA pools, two sets of three inbred lines were considered: EP1 - F2 - LO3 (European Flint inbred lines) and NYS302- EA1433 - M37W (Tropical inbred lines). For each set of parental lines, nine controlled pools were prepared by varying the proportion of each line in the mix, quantified by the number of leaf disks of equal size as per Dubreuil et al., (32). The genotype of each line and the proportion of parental lines in each pool were used to estimate allelic frequencies in the nine pools, and subsequently to calibrate the model for predicting allelic frequency (see (51) for more detail).

\section{Genotyping and prediction of allelic frequencies in DNA pools}

We used the $50 \mathrm{~K}$ Illumina Infinium HD array (37) to genotype (i) landraces, (ii) controlled DNA pools, (iii) the DH-SSD inbred lines and (iv) the parental lines of the controlled DNA pools(Table S1 and S11). For CK lines, we used the 50K genotyping data from Bouchet et al. (2013). 23,412 SNPs were filtered based on their suitability for diversity 
520 analysis and their quality for predicting allelic frequency in DNA pools (Supplementary 521 Information 2).

522 Allelic frequency of selected SNPs in DNA pools was estimated using the two-step 523 procedure described in (51) based on the fluorescence intensity ratio (FIR) of alleles A and B 524 for each SNP. First, we tested whether SNPs were monomorphic or polymorphic. For SNPs 525 that were considered to be polymorphic, we then estimated the allelic frequency of the B 526 allele using a generalized linear model calibrated on FIR data from 1,000 SNPs from 2 series 527 of controlled pools (see (51) for more detail and equation 2 for the model).

528 We also used the genotyping data from 17 SSRs from 145 and 11 landraces obtained by 529 Camus-Kulandaivelu et al. (27) and Mir et al. (23), respectively.

\section{Diversity analyses}

\section{Estimation of genetic diversity parameters}

For each landrace, each geographic group, all landraces combined and the panel of inbred lines, we determined for each locus: the mean allele number (A), the Minor Allele Frequency (MAF) and the expected heterozygosity $(\mathrm{H})(80,81)$.

Genetic differentiation (FST) was estimated between: individual landraces $\left(\mathrm{FST}_{1}\right)$, between the five landrace geographic groups $\left(\mathrm{FST}_{\mathrm{g}}\right)$, between 10 pairs of geographic groups

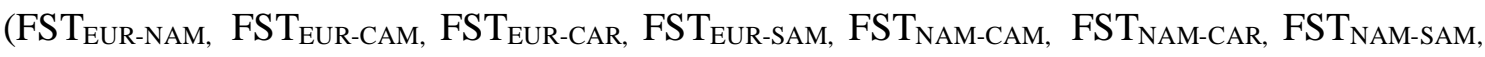
FST $_{\text {CAM-CAR, }}$ FST $_{\text {CAM-SAM, }}$ FST $_{\text {CAR-SAM }}$ ) and between landraces and inbred lines $\left(\right.$ FST $\left._{\mathrm{i}}\right)$. FST was estimated at each locus and across all loci as per (81, 82) (Supplementary Information 3).

\section{Genome-wide diversity analysis and scans for identifying selection signatures}

We used a sliding window of $1 \mathrm{Mbp}$, shifting by $500 \mathrm{kbp}$ at each step along the genome, to analyze the genome-wide variation in genetic diversity and differentiation between landraces, between geographic groups, and between landraces and inbred lines. The maize genome was divided into 4,095 overlapping windows containing an average of $11.3 \pm 5.2$ SNPs. We computed the average value for the parameters described above for all loci in a given window. Outlier regions for $\mathrm{H}$ and FST were identified based on the distribution of these parameters for individual loci over the entire genome using the 5 th and $95^{\text {th }}$ percentile (below 5\% and above 95\%) as thresholds (Table S4). All statistics were computed using ad hoc scripts in the R language v 3.0.3 (83). 
Genomic scans were carried out to detect the genomic signature of selection between

551

552

553

554

555

556

557

558

559

560

561

562

563

564

565

566

567

568

569

570

571

572

573

574

575

576

577

578

579

580

landraces, between the five geographic groups and between landraces and inbred lines using two approaches: (i) the detection of $1 \mathrm{Mbp}$ regions that were outliers for FST, referred to as "Outlier FST analysis" (ii) the detection of loci under selection using the drift model implemented in the BAYESCAN software (84) (Supplementary Information 4).

\section{Genetic structure and relationship between landraces}

We estimated the genetic distance between all landraces using modified Roger's distance (MRD) (85) based on the allelic frequencies of 23,412 prefixed PZE SNPs. MRD was then averaged within and between geographic groups (Table 1, Table S2). We analyzed the relationship between genetic and geographic distances within each geographic group by plotting MRD against geographic distances. We tested this correlation using the Mantel test (86). Geographic distances were calculated using the latitude and longitude of each sampling site using the geosphere R package v. 1.5-10 (87).

To decipher the structure of genetic diversity within our panel of landraces from 23,412 filtered SNPs, we used two approaches:

1) A distance-based approach in which MRDs between the 166 landraces were used to perform (i) a principal coordinate analysis (PCoA) (88), (ii) hierarchical clustering using either Ward or Neighbor-Joining algorithms implemented in the "hc" and "bionj" functions of the "ape" R package v 5.0 (89), respectively.

2) A Bayesian multi-locus approach, implemented in the ADMIXTURE software, to assign probabilistically each landrace to $\mathrm{K}$ ancestral populations assumed to be in HardyWeinberg Equilibrium (90). Different methods were used to identify the most appropriate number of ancestral populations (K): Cross-validation error or difference between successive cross-validations (90) and Evanno's graphical methods (91). Since ADMIXTURE requires multi-locus genotypes of individual plants, we simulated the genotype of five individuals for each population for a subset of 2,500 independent SNPs to avoid artifacts of linkage disequilibrium (Supplementary Information 5).

\section{Contribution of populations to inbred lines using supervised analysis}

\section{and modified Roger's distance}

To analyze the contribution of landraces to the modern breeding germplasm, we used two different approaches: 
1) A distance-based approach in which we estimated the modified Roger's distance between each landrace and the $327 \mathrm{CK}$ lines (MDRLI) in order to determine whether they are related or not.

2) A Bayesian supervised approach implemented in ADMIXTURE in which the 442 inbred lines were assigned probabilistically to the 166 landrace populations in order to identify the most likely source population of each inbred line (Table S11). For each landrace, we estimated (i) its average contribution to $\mathrm{CK}$ lines by averaging the assignment probability over 327 lines and (ii) the number of inbred lines mainly assigned to this landrace, with an assignment probability $>60 \%$. We also analyzed the evolution of the contribution of landraces across breeding cycles by comparing contributions to (i) first cycle lines and (ii) advanced lines from the CK line panel. To check the accuracy of the assignment method, we estimated the percentage of first cycle lines that were correctly assigned to their parental landrace as known from their pedigree and analyzed in our study (121 of the 234 first cycle lines, known to be derived from 50 landraces). We tested if this percentage was different between CK lines and DH-SSD lines using a Kruskal-Wallis chisquared test. To represent each landrace, we used the same five simulated individuals as in the structure analysis.

Identification of landraces that could enrich the modern breeding germplasm We assessed

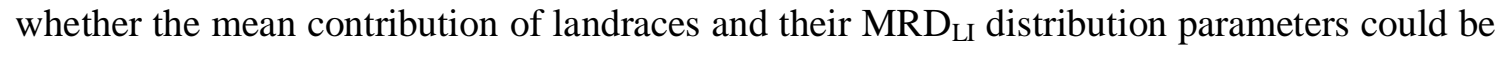
used as criteria to identify landraces that could enrich the modern breeding germplasm. To this end, allelic diversity was estimated in the two inbred panels (DH-SSD and CK lines) for 979 haplotypes. These haplotype markers were defined by genotyping triplets of adjacent SNPs from $50 \mathrm{~K}$ arrays that were less than $2 \mathrm{kbp}$ apart. We estimated the average number of new haplotypes discovered in the DH-SSD lines compared to those in the $327 \mathrm{CK}$ lines. To avoid noise due to seedlot error during DH-SSD line production, we selected 66 DH-SSD lines that were correctly assigned to 33 landraces analyzed from this study.

To analyze the effect of mean contribution, we classified these 33 landraces into three classes: low, intermediate, and high contribution based on the 30 th and $90^{\text {th }}$ percentile of the distribution of mean landrace contribution to CK lines.

To analyze the usefulness of $\mathrm{MRD}_{\mathrm{LI}}$, we took into account the negative correlation between $\mathrm{MRD}_{\mathrm{LI}}$ and within-gene diversity of landraces (Hs), which could strongly bias against landraces with the lowest within diversity. For each landrace, we defined a "normalized" $\mathrm{MRD}$ distance $\left(\mathrm{MRD}_{\text {norm}}\right)$ based on the absolute difference between (i) the 
614 median $\mathrm{MRD}_{\mathrm{LI}}$ between a landrace and lines of $\mathrm{CK}$ panel $\left(\mathrm{MRD}_{\text {med }}\right)$ and (ii) the $\mathrm{MRD}_{\mathrm{LI}}$ from 615 the closest lines $\left(\mathrm{MRD}_{\mathrm{q}}\right)$ defined by the 5th (MRD05) and 10 ${ }^{\text {th }}$ (MRD10) percentile of $616 \mathrm{MRD}_{\mathrm{LI}}$, corresponding to the 5 and $10 \%$ closest lines. In order to correct the bias due to Hs, 617 we used the linear regression coefficient "a" between $M R D_{\text {med }}$ and Hs. We defined $\mathrm{MRD}_{\text {norm }}$ 618 as the orthogonal deviation of $\mathrm{MRD}_{\mathrm{q}}$ (with $\mathrm{q}=5 \%$ or $10 \%$ for $\mathrm{MRD}_{05}$ and $\mathrm{MRD}_{10}$, 619 respectively) from the linear regression:

$$
M R D_{\text {norm }}=\left(M R D_{\text {med }}-M R D_{q}\right) \times \sin \left(\tan ^{-1}(a)\right)(1)
$$

621 We used $\mathrm{MRD}_{\text {norm }}$ based on $\mathrm{MRD}_{10}$ to categorize the 33 landraces into three classes based 622 on the percentile distribution of $\mathrm{MRD}_{\text {norm. }}$. Landraces with $\mathrm{MRD}_{\text {norm }}$ below $30 \%$, between $30 \%$ 623 and $70 \%$ quantile and above $70 \%$ were considered to have none, few or many derived lines, 624 respectively.

625 Finally, we performed a variance analysis to test the effect of mean contribution and 626 $\mathrm{MRD}_{\text {norm }}$ on the number of new haplotypes discovered in the DH-SSD lines.

\section{Acknowledgements}

628 This study was funded by the" Association pour l'étude et l'amélioration du maïs" (PROmais) within the "Diversity Zea" project and the French National Research Agencies with thein

630 “Investissement d'Avenir Amaizing” project, (ANR-10-BTBR-01). We greatly acknowledge 631 the French Maize Biological Ressource Center, PROmais, and the INRAE experimental units 632 of St Martin de Hinx and Mauguio for collecting and maintaining the collection of landraces 633 and inbred lines. We greatly acknowledge colleagues who initially collected these landraces 634 and André Gallais for initiating these research programs. We also greatly acknowledge Pierre 635 Dubreuil, Letizia Camus-Kulandaivelu, Cecile Rebourg, Céline Mir, Domenica Maniccaci 636 who conducted previous studies on these landraces using the DNA pooling approach with 637 SSR and RFLP markers. The Infinium genotyping work was supported by CEA-CNG. We 638 thank Anne Boland and Marie-Thérèse Bihoreau and their staff. We acknowledge the EPGV 639 group, Dominique Brunel, Aurélie Bérard and Aurélie Chauveau for discussion and 640 management of Illumina genotyping.

\section{Author contributions}


642 S.D.N, A.C and B.G designed and supervised the study and selected the plant material; M.A,

643 S.D.N, A.C, B.G drafted and corrected the manuscript; D.M, V.C and M-C.L-P extracted

644 DNA and managed the genotyping of landraces and inbred lines; C.B, B.G and A.C collected

645 andmaintained the collection of landraces and inbred lines; S.D.N, M.A, A.C and T.M-H

646 developed the statistical methods for predicting allelic frequency from fluorescence data;

647 M.A, B.G and S.D.N analyzed the genetic diversity of the landrace panel; M.A and S.D.N

648 analyzed the selective sweep; MA, S.D.N and A.C investigated the relationship between

649 landraces and inbred lines; S.D.N developed the normalized distance measure and performed

650 the analysis of diversity enrichment.

\section{Data availability}

652 Fluorescence Intensity Data from 166 DNA samples of landraces used for predicting allelic

653 frequency and modified Roger's distance matrix are available at 654 https://doi.org/10.15454/D4JTKB. To predict allelic frequency in 166 DNA pools, we 655 calibrated our two-step model with fluorescence intensity data of 327 inbred lines (for 656 calibrating the fixation test) and two series of controlled pools (for calibrating logistic 657 regression) with $\mathrm{R}$ script that are available at the following address: 658 https://doi.org/10.15454/GANJ7J. Note that data will be available at the two web links below 659 upon the publication will have been accepted in a journal.

\section{Conflicts of interest}

661 No

662 


\section{REFERENCES}

664 1. S. D. Tanksley, Seed Banks and Molecular Maps: Unlocking Genetic Potential from the 665 Wild. Science 277, 1063-1066 (1997).

666 2. D. Hoisington, et al., Plant genetic resources: What can they contribute toward increased 667 crop productivity? Proc. Natl. Acad. Sci. 96, 5937-5943 (1999).

668 3. B. Kilian, A. Graner, NGS technologies for analyzing germplasm diversity in 669 genebanks*. Brief. Funct. Genomics 11, 38-50 (2012).

670

4. S. R. McCouch, K. L. McNally, W. Wang, R. Sackville Hamilton, Genomics of gene banks: A case study in rice. Am. J. Bot. 99, 407-423 (2012).

672

5. A. R. Fernie, Y. Tadmor, D. Zamir, Natural genetic variation for improving crop quality. Curr. Opin. Plant Biol. 9, 196-202 (2006).

674

6. M. Mascher, et al., Genebank genomics bridges the gap between the conservation of

675 crop diversity and plant breeding. Nat. Genet. 51, 1076-1081 (2019).

676

677

678

7. D. J. Gates, et al., "Single-gene resolution of locally adaptive genetic variation in Mexican maize" (Evolutionary Biology, 2019) https:/doi.org/10.1101/706739 (September 25, 2020).

679

8. J. C. Reif, et al., Wheat genetic diversity trends during domestication and breeding.

680

681

682

683

9. M. Yamasaki, et al., A large-scale screen for artificial selection in maize identifies candidate agronomic loci for domestication and crop improvement. Plant Cell 17, 28592872 (2005).

684

10. M. Yamasaki, S. I. Wright, M. D. McMullen, Genomic screening for artificial selection during domestication and improvement in maize. Ann. Bot. 100, 967-973 (2007).

686

687

11. E. S. Buckler, B. S. Gaut, M. D. McMullen, Molecular and functional diversity of maize. Curr. Opin. Plant Biol. 9, 172-176 (2006).

688

689

690

691

692

693

694

695

696
12. J. T. Gerdes, W. F. Tracy, Pedigree Diversity within the Lancaster Surecrop Heterotic Group of Maize. Crop Sci. 33, 334-337 (1993).

13. J. van Heerwaarden, et al., Genetic signals of origin, spread, and introgression in a large sample of maize landraces. Proc. Natl. Acad. Sci. 108, 1088-1092 (2011).

14. M. A. Mikel, Genetic Composition of Contemporary U.S. Commercial Dent Corn Germplasm. Crop Sci. 51, 592-599 (2011).

15. S. M. Coffman, M. B. Hufford, C. M. Andorf, T. Lübberstedt, Haplotype structure in commercial maize breeding programs in relation to key founder lines. Theor. Appl. Genet. 133, 547-561 (2020). 
16. A. Strigens, W. Schipprack, J. C. Reif, A. E. Melchinger, Unlocking the Genetic Diversity of Maize Landraces with Doubled Haploids Opens New Avenues for Breeding. PLoS ONE 8, e57234 (2013).

17. P. C. Brauner, et al., Testcross performance of doubled haploid lines from European flint maize landraces is promising for broadening the genetic base of elite germplasm. Theor. Appl. Genet. 132, 1897-1908 (2019).

18. A. C. Hölker, et al., European maize landraces made accessible for plant breeding and genome-based studies. Theor. Appl. Genet. 132, 3333-3345 (2019).

19. G. W. Beadle, Teosinte and the origin of maize. J. Hered. 30, 245-247 (1939).

20. Y. Matsuoka, et al., A single domestication for maize shown by multilocus microsatellite genotyping. Proc. Natl. Acad. Sci. 99, 6080-6084 (2002).

21. M. I. Tenaillon, A. Charcosset, A European perspective on maize history. $C$. R. Biol. (2011).

22. K. Swarts, et al., Genomic estimation of complex traits reveals ancient maize adaptation to temperate North America. Science 357, 512-515 (2017).

23. C. Mir, et al., Out of America: tracing the genetic footprints of the global diffusion of maize. Theor. Appl. Genet. 126, 2671-2682 (2013).

24. A. Brandolini, Maize. Maize. (1970).

25. C. Rebourg, B. Gouesnard, A. Charcosset, Large scale molecular analysis of traditional European maize populations. Relationships with morphological variation. Heredity 86, 574-587 (2001).

26. C. Rebourg, et al., Maize introduction into Europe: the history reviewed in the light of molecular data. Theor Appl Genet 106, 895-903 (2003).

27. L. Camus-Kulandaivelu, Maize Adaptation to Temperate Climate: Relationship Between Population Structure and Polymorphism in the Dwarf8 Gene. Genetics 172, 2449-2463 (2006).

28. P. Dubreuil, M. Warburton, M. Chastanet, D. Hoisington, A. Charcosset, More on the introduction of temperate maize into Europe: large-scale bulk SSR genotyping and new historical elements (2006).

29. J.-T. Brandenburg, et al., Independent introductions and admixtures have contributed to adaptation of European maize and its American counterparts. PLoS Genet. 13, e1006666 (2017).

30. L. Wang, et al., "Molecular Parallelism Underlies Convergent Highland Adaptation of Maize Landraces" (Evolutionary Biology, 2020) https:/doi.org/10.1101/2020.07.31.227629 (September 25, 2020). 
31. P. Dubreuil, A. Charcosset, Genetic diversity within and among maize populations: a comparison between isozyme and nuclear RFLP loci. Theor. Appl. Genet. 96, 577-587 (1998).

32. P. Dubreuil, C. Rebourg, M. Merlino, A. Charcosset, Evaluation of a DNA pooledsampling strategy for estimating the RFLP diversity of maize populations. Plant Mol Biol Rep 17, 123-138 (1999).

33. C. Rebourg, P. Dubreuil, A. Charcosset, Genetic diversity among maize populations: bulk RFLP analysis of 65 accessions. Maydica 44, 237-249 (1999).

34. P. Gauthier, et al., RFLP diversity and relationships among traditional European maize populations. Theor Appl Genet 105, 91-99 (2002).

35. Y. Vigouroux, et al., An analysis of genetic diversity across the maize genome using microsatellites. Genetics 169, 1617-1630 (2005).

36. T. W. Eschholz, P. Stamp, R. Peter, J. Leipner, A. Hund, Genetic structure and history of Swiss maize (Zea mays L. ssp. mays) landraces. Genet. Resour. Crop Evol. 57, 71-84 (2010).

37. M. W. Ganal, et al., A Large Maize (Zea mays L.) SNP Genotyping Array: Development and Germplasm Genotyping, and Genetic Mapping to Compare with the B73 Reference Genome. PLoS ONE 6, e28334 (2011).

38. S. R. McCouch, et al., Development of genome-wide SNP assays for rice. Breed. Sci. 60, 524-535 (2010).

39. M. Moragues, et al., Effects of ascertainment bias and marker number on estimations of barley diversity from high-throughput SNP genotype data. Theor. Appl. Genet. 120, 1525-1534 (2010).

40. A. Rafalski, Applications of single nucleotide polymorphisms in crop genetics. Curr Opin Plant Biol 5, 94-100 (2002).

41. M. B. Hufford, et al., Comparative population genomics of maize domestication and improvement. Nat. Genet. (2012) https:/doi.org/10.1038/ng.2309 (July 11, 2012).

42. S. Bouchet, et al., Adaptation of maize to temperate climates: mid-density genome-wide association genetics and diversity patterns reveal key genomic regions, with a major contribution of the Vgt2 (ZCN8) locus. PloS One 8, e71377 (2013).

43. E. Frascaroli, T. A. Schrag, A. E. Melchinger, Genetic diversity analysis of elite European maize (Zea mays L.) inbred lines using AFLP, SSR, and SNP markers reveals ascertainment bias for a subset of SNPs. Theor. Appl. Genet. 126, 133-141 (2013).

44. M. C. Arteaga, et al., Genomic variation in recently collected maize landraces from Mexico. Genomics Data 7, 38-45 (2016).

45. M. H. Reyes-Valdés, et al., Analysis and Optimization of Bulk DNA Sampling with Binary Scoring for Germplasm Characterization. PLoS ONE 8, e79936 (2013). 
46. P. Sham, J. S. Bader, I. Craig, M. O’Donovan, M. Owen, DNA Pooling: a tool for largescale association studies. Nat. Rev. Genet. 3, 862-871 (2002).

47. C. Schlötterer, R. Tobler, R. Kofler, V. Nolte, Sequencing pools of individuals mining genome-wide polymorphism data without big funding. Nat. Rev. Genet. 15, 749763 (2014).

48. J. C. Reif, et al., Grouping of accessions of Mexican races of maize revisited with SSR markers. Theor. Appl. Genet. 113, 177-185 (2006).

49. Q. Yao, K. Yang, G. Pan, T. Rong, Genetic diversity of maize (Zea mays L.) landraces from Southwest China based on SSR data. J. Genet. Genomics 34, 851-860 (2007).

50. S. Unterseer, et al., A powerful tool for genome analysis in maize: development and evaluation of the high density 600k SNP genotyping array. BMC Genomics 15, 823 (2014).

51. M. Arca, et al., Deciphering the genetic diversity of landraces with high-throughput SNP genotyping of DNA bulks: methodology and application to the maize 50k array. bioRxiv (2020) https:/doi.org/10/gg8nxn (June 4, 2020).

52. M. T. Hamblin, M. L. Warburton, E. S. Buckler, Empirical Comparison of Simple Sequence Repeats and Single Nucleotide Polymorphisms in Assessment of Maize Diversity and Relatedness. PLoS ONE 2, e1367 (2007).

53. A. G. Clark, M. J. Hubisz, C. D. Bustamante, S. H. Williamson, R. Nielsen, Ascertainment bias in studies of human genome-wide polymorphism. Genome Res. 15, 1496-1502 (2005).

54. A. Albrechtsen, F. C. Nielsen, R. Nielsen, Ascertainment Biases in SNP Chips Affect Measures of Population Divergence. Mol. Biol. Evol. 27, 2534-2547 (2010).

55. J. A. Romero Navarro, et al., A study of allelic diversity underlying flowering-time adaptation in maize landraces. Nat. Genet. 49, 476-480 (2017).

56. J. Böhm, W. Schipprack, H. F. Utz, A. E. Melchinger, Tapping the genetic diversity of landraces in allogamous crops with doubled haploid lines: a case study from European flint maize. Theor. Appl. Genet. 130, 861-873 (2017).

57. L. Zeitler, J. Ross-Ibarra, M. G. Stetter, "Loss of diversity and accumulation of genetic load in doubled-haploid lines from European maize landraces" (Evolutionary Biology, 2019) https:/doi.org/10.1101/817791 (February 5, 2020).

58. P. Dubreuil, A. Charcosset, Relationships among maize inbred lines and populations from European and North-American origins as estimated using RFLP markers. Theor. Appl. Genet. 99, 473-480 (1999).

59. Y. Diaw, et al., "Genetic diversity of maize landraces from the South-West of France" (Genetics, 2020) https:/doi.org/10.1101/2020.08.17.253690 (September 3, 2020).

60. P. Revilla, P. Soengas, R. A. Malvar, M. E. Cartea, A. Ordás, Isozyme variation and historical relationships among the maize races of Spain. Maydica 43, 175-182 (1998). 
807

808

809

810

811

812

813

814

815

816

817

818

819

820

821

822

823

824

825

826

827

828

829

830

831

832

833

834

835

836

837

838

839

840

841

61. J. A. Aguirre-Liguori, et al., Connecting genomic patterns of local adaptation and niche suitability in teosintes. Mol. Ecol. 26, 4226-4240 (2017).

62. E. Millet, et al., Genome-wide analysis of yield in Europe: allelic effects as functions of drought and heat scenarios. Plant Physiol., pp.00621.2016 (2016).

63. P. Revilla, W. F. Tracy, Isozyme Variation and Phylogenetic Relationhips among OpenPollinated Sweet Corn Cultivars. Crop Sci. 35, 219-227 (1995).

64. S. Whitt, L. Wilson, M. Tenaillon, B. Gaut, E. Buckler, Genetic diversity and selection in the maize starch pathway. Proc. Natl. Acad. Sci. U. S. A. 99, 12959 (2002).

65. V. Jaenicke-Despres, et al., Early allelic selection in maize as revealed by ancient DNA. Science 302, 1206-1208 (2003).

66. W. F. Tracy, S. R. Whitt, E. S. Buckler, Recurrent Mutation and Genome Evolution: Example of and the Origin of Sweet Maize. Crop Sci. 46, S-49 (2006).

67. M. C. Romay, et al., Comprehensive genotyping of the USA national maize inbred seed bank. Genome Biol 14, R55 (2013).

68. B. Gouesnard, et al., Genotyping-by-sequencing highlights original diversity patterns within a European collection of 1191 maize flint lines, as compared to the maize USDA genebank. Theor. Appl. Genet. (2017) https:/doi.org/10.1007/s00122-017-2949-6 (August 8, 2017).

69. C. Huang, et al., ZmCCT9 enhances maize adaptation to higher latitudes. Proc. Natl. Acad. Sci., 201718058 (2017).

70. S. S. Negro, et al., Genotyping-by-sequencing and SNP-arrays are complementary for detecting quantitative trait loci by tagging different haplotypes in association studies. BMC Plant Biol. 19, 318 (2019).

71. L. Virlouvet, et al., The ZmASR1 Protein Influences Branched-Chain Amino Acid Biosynthesis and Maintains Kernel Yield in Maize under Water-Limited Conditions. Plant Physiol. 157, 917-936 (2011).

72. A. Yilmaz, et al., GRASSIUS: A Platform for Comparative Regulatory Genomics across the Grasses. Plant Physiol. 149, 171-180 (2009).

73. Y. Gu, et al., Genome-wide identification and abiotic stress responses of DGK gene family in maize. J. Plant Biochem. Biotechnol. (2017) https:/doi.org/10/gd5758 (July 17, 2020).

74. B. Wang, et al., Genome-wide selection and genetic improvement during modern maize breeding. Nat. Genet. 52, 565-571 (2020).

75. D. L. Hyten, et al., Impacts of genetic bottlenecks on soybean genome diversity. Proc. Natl. Acad. Sci. 103, 16666-16671 (2006). 
842

862

863

864

865

866

867

868

869

870

871

872

76. C. R. Cavanagh, et al., Genome-wide comparative diversity uncovers multiple targets of selection for improvement in hexaploid wheat landraces and cultivars. Proc. Natl. Acad. Sci. 110, 8057-8062 (2013).

77. S. I. Wright, et al., The effects of artificial selection of the maize genome. Science $\mathbf{3 0 8}$, 1310-1314 (2005).

78. Y. Jiao, et al., Genome-wide genetic changes during modern breeding of maize. Nat. Genet. 44, 812-815 (2012).

79. M. A. Gore, et al., A first-generation haplotype map of maize. Sci. Wash. 326, 11151117 (2009).

80. M. Nei, Analysis of gene diversity in subdivided populations. Proc Natl Acad Sci U A 70, 3321-3 (1973).

81. M. Nei, F-statistics and analysis of gene diversity in subdivided populations. Ann Hum Genet 41, 225-33 (1977).

82. S. Wright, The genetical structure of populations. Ann. Hum. Genet. 15, 323-354 (1949).

83. R Core Team, $R$ : A language and environment for statistical computing (R Foundation for Statistical Computing, 2013).

84. M. Foll, O. E. Gaggiotti, Colonise: a computer program to study colonization processes in metapopulations. Mol Ecol Notes 5, 705-707 (2005).

85. J. S. Rogers, Measures of genetic similarity and genetic distance. Stud. Genet. 7, 145153 (1972).

86. P. E. Smouse, J. C. Long, R. R. Sokal, Multiple regression and correlation extensions of the Mantel test of matrix correspondence. Syst. Zool. 35, 627-632 (1986).

87. R. J. Hijmans, geosphere: Spherical Trigonomery. R package version 1.5-10 (2019).

88. J. C. Gower, Some distance properties of latent root and vector methods used in multivariate analysis. Biometrika 53, 325-338 (1966).

89. E. Paradis, K. Schliep, ape 5.0: an environment for modern phylogenetics and evolutionary analyses in R. Bioinformatics 35, 526-528 (2019).

90. D. H. Alexander, J. Novembre, K. Lange, Fast model-based estimation of ancestry in unrelated individuals. Genome Res. 19, 1655-1664 (2009).

91. G. Evanno, S. Regnaut, J. Goudet, Detecting the number of clusters of individuals using the software Structure: a simulation study. Mol Ecol 14, 2611-2620 (2005). 
Table 1: Genetic diversity within the five geographic groups of landraces, the entire landrace panel and the CK line panel.

\begin{tabular}{|c|c|c|c|c|c|c|c|}
\hline & $\begin{array}{c}\text { Europe } \\
\text { (EUR) } \\
\text { mean } \pm \text { s.d. }\end{array}$ & $\begin{array}{l}\text { North America } \\
\text { (NAM) } \\
\text { mean } \pm \text { s.d. }\end{array}$ & $\begin{array}{c}\text { Central America } \\
\text { and Mexico } \\
\text { (CAM) } \\
\text { mean } \pm \text { s.d. }\end{array}$ & $\begin{array}{l}\text { Caribbean (CAR) } \\
\text { mean } \pm \text { s.d. }\end{array}$ & $\begin{array}{l}\text { South America } \\
\text { (SAM) } \\
\text { mean } \pm \text { s.d. }\end{array}$ & $\begin{array}{l}\text { Landrace Panel } \\
\text { (LP) } \\
\text { mean } \pm \text { s.d. }\end{array}$ & $\begin{array}{l}\text { CK line Panel (IL) } \\
\text { mean } \pm \text { s.d. }\end{array}$ \\
\hline Number of populations / inbred lines & 83 & 22 & 25 & 14 & 22 & 166 & 327 \\
\hline $\begin{array}{l}\text { Allele Number (A) } \\
\text { group level }\end{array}$ & $1.996 \pm 0.001$ & $1.989 \pm 0.005$ & $1.990 \pm 0.004$ & $1.947 \pm 0.017$ & $1.992 \pm 0.004$ & $1.999 \pm 0.000$ & $1.989 \pm 0.001$ \\
\hline $\begin{array}{l}\text { Allele Number (A) } \\
\text { average within pop/line }\end{array}$ & $1.584 \pm 0.005$ & $1.649 \pm 0.021$ & $1.701 \pm 0.018$ & $1.662 \pm 0.034$ & $1.671 \pm 0.021$ & $1.629 \pm 0.003$ & $1.004 \pm 0.000$ \\
\hline $\begin{array}{l}\text { Minor Allele Frequency (MAF) } \\
\text { group level }\end{array}$ & $0.235 \pm 0.001$ & $0.235 \pm 0.006$ & $0.244 \pm 0.006$ & $0.223 \pm 0.011$ & $0.240 \pm 0.007$ & $0.253 \pm 0.001$ & $0.265 \pm 0.001$ \\
\hline $\begin{array}{l}\text { Minor Allele Frequency (MAF) } \\
\text { average within pop/line }\end{array}$ & $0.128 \pm 0.001$ & $0.141 \pm 0.002$ & $0.159 \pm 0.001$ & $0.150 \pm 0.001$ & $0.149 \pm 0.001$ & $0.139 \pm 0.000$ & $0.002 \pm 0.000$ \\
\hline $\begin{array}{l}\text { Total expected heterozygosity } \\
\text { across groups }(\mathrm{HT})\end{array}$ & $0.314 \pm 0.002$ & $0.317 \pm 0.007$ & $0.328 \pm 0.006$ & $0.301 \pm 0.012$ & $0.323 \pm 0.007$ & $0.338 \pm 0.001$ & $0.353 \pm 0.001$ \\
\hline $\begin{array}{l}\text { Expected heterozygosity (Hs) } \\
\text { average of within pop / line }\end{array}$ & $0.177 \pm 0.002$ & $0.195 \pm 0.009$ & $0.219 \pm 0.008$ & $0.206 \pm 0.014$ & $0.205 \pm 0.009$ & $0.0192 \pm 0.001$ & $0.002 \pm 0.000$ \\
\hline $\begin{array}{l}\text { Modified Roger's Distance between landraces / } \\
\text { inbred lines (MRD) }\end{array}$ & $0.367 \pm 0.061$ & $0.351 \pm 0.063$ & $0.336 \pm 0.033$ & $0.320 \pm 0.026$ & $0.346 \pm 0.068$ & $0.379 \pm 0.059$ & $0.580 \pm 0.024$ \\
\hline $\begin{array}{c}\text { Differentiation between landraces }\left(\mathrm{FST}_{\mathrm{I}}\right) \text { and } \\
\text { between inbred lines }\left(\mathrm{FST}_{\mathrm{i}}\right)\end{array}$ & $0.393 \pm 0.001$ & $0.341 \pm 0.001$ & $0.303 \pm 0.001$ & $0.275 \pm 0.001$ & $0.334 \pm 0.001$ & $0.405 \pm 0.002$ & 0.994 \\
\hline
\end{tabular}


Table 2: Genomic regions identified as being highly differentiated between landraces and geographic groups. Only SNPs that were detected by BAYESCAN with decisive evidence of selection and Outlier FST windows carrying at least two SNPs are listed.

\begin{tabular}{|c|c|c|c|c|c|c|c|c|c|c|c|c|c|c|c|c|c|c|c|}
\hline \multicolumn{8}{|c|}{ Outlier FST windows } & \multicolumn{7}{|c|}{ Bayescan hits (Decisive) - Geographical } & \multicolumn{4}{|c|}{ Frequency of allele B } & \\
\hline Name $^{*}$ & $\mathrm{Chr}$ & $\begin{array}{l}\text { Start - } \\
\text { Stop } \\
\text { (Mbp) }\end{array}$ & $\mathrm{SNP}_{\mathrm{w}}$ & $\mathrm{FST}_{\mathrm{g}}$ & $\mathrm{FST}_{1}$ & $\mathrm{HT}_{1}$ & Hs & $\mathrm{SNP}_{\mathrm{b}}$ & Marker name & $\begin{array}{l}\text { Pos. } \\
(\mathrm{Mbp})\end{array}$ & $\mathrm{FST}_{\mathrm{b}}$ & Closest Gene & $\begin{array}{l}\text { Dist. } \\
\text { from } \\
\text { gene } \\
\text { (kbp) }\end{array}$ & Functionnal annotation & EUR & NAM & CAM & CAR & $\mathrm{S}$ \\
\hline \multirow{3}{*}{$\begin{array}{l}\mathrm{Sg} 1 \\
\mathrm{Sp} 2\end{array}$} & \multirow{3}{*}{3} & 77.5 & \multirow{3}{*}{4} & \multirow{3}{*}{0.15} & \multirow{3}{*}{0.54} & \multirow{3}{*}{0.39} & \multirow{3}{*}{0.15} & \multirow{3}{*}{4} & PZE-103058385 & 78.2 & 0.26 & GRMZM2G584078 & \multirow{2}{*}{\multicolumn{2}{|c|}{$\begin{array}{l}4 \\
0\end{array}$}} & 0.76 & 0.73 & 0.39 & 0.00 & \\
\hline & & - & & & & & & & PZE-103058429 & 78.5 & 0.30 & AC202959.3_FG001 & & & $0 . .30$ & $0 . .34$ & 0.72 & 1.00 & \\
\hline & & & & & & & & & PZE-103058437 & 78.5 & 0.29 & GRMZM2G112187 & 6 & & 0.69 & 0.67 & 0.32 & 0.00 & \\
\hline \multirow{3}{*}{$\begin{array}{l}\mathrm{Sg} 2 \\
\mathrm{Sp} 3\end{array}$} & \multirow{3}{*}{3} & 84 & \multirow{3}{*}{3} & \multirow{3}{*}{0.18} & \multirow{3}{*}{0.63} & \multirow{3}{*}{0.50} & \multirow{3}{*}{0.19} & \multirow{3}{*}{3} & PZE-103059206 & 82.1 & 0.26 & GRMZM2G154496 & 0 & \multirow{3}{*}{$\begin{array}{l}\text { Pectin lyase-like superfamily } \\
\text { protein }\end{array}$} & 0.71 & 0.67 & 0.33 & 0.00 & \\
\hline & & $\begin{array}{l}04 \\
-\end{array}$ & & & & & & & PZE-107023081 & 84.9 & 0.29 & \multirow{2}{*}{ GRMZM2G112579 } & 5.6 & & 0.69 & 0.65 & 0.32 & 0.00 & \\
\hline & & 85 & & & & & & & PZE-107023082 & 84.9 & 0.29 & & 5.7 & & 0.31 & 0.35 & 0.64 & 1.00 & \\
\hline \multirow{5}{*}{$\begin{array}{l}\mathrm{Sg} 4 \\
\mathrm{Sp} 6\end{array}$} & \multirow{5}{*}{4} & & \multirow{5}{*}{7} & \multirow{5}{*}{0.27} & \multirow{5}{*}{0.63} & & & & PZE-104010475 & 7.6 & 0.30 & СРМСМ 2С012821 & 0 & E hor protoin & 0.04 & 0.06 & 0.77 & 0.19 & \\
\hline & & & & & & & & & PZE-104010477 & 7.6 & 0.31 & GRIVZMLGOIZ8Z1 & 0 & F-box protein & 0.97 & 0.95 & 0.24 & 0.83 & \\
\hline & & $\begin{array}{c}7.8 \\
-\end{array}$ & & & & 0.23 & 0.07 & 6 & PZE-104010709 & 8.8 & 0.30 & GRMZM2G119698 & 0 & pectinesterase & 0.06 & 0.06 & 0.79 & 0.29 & \\
\hline & & 9.4 & & & & & & & PZE-104010719 & 8.8 & 0.28 & GRMZM2G702341 & 0.2 & & 0.98 & 0.95 & 0.34 & 0.95 & $0 . \frac{10}{8}$ \\
\hline & & & & & & & & & PZE-104010855 & 9.4 & 0.27 & GRMZM2G419836 & 0 & $\begin{array}{l}\text { Thioredoxin superfamily } \\
\text { protein }\end{array}$ & 0.98 & 0.96 & 0.42 & 0.80 & 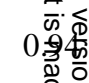 \\
\hline & & & & & & & & & PZE-104033199 & 41.2 & 0.26 & GRMZM5G889780 & 13.7 & & 0.43 & 0.28 & 0.90 & 1.00 & \\
\hline $\mathrm{Sg} 5$ & 4 & $\begin{array}{c}40.9 \\
-\end{array}$ & 7 & 0.16 & 0.63 & 0.44 & 0.16 & 4 & PZE-104033229 & 41.4 & 0.28 & GRMZM2G138198 & 0 & Pollen receptor-like kinase 4 & 0.49 & 0.66 & 0.06 & 0.00 & \\
\hline & & 41.9 & & & & & & & PZE-104033340 & 41.7 & 0.27 & GRMZM2G174149 & 0 & $\begin{array}{l}\text { RNA pseudouridine synthase } \\
3 \text { mitochondrial }\end{array}$ & 0.54 & 0.39 & 0.94 & 1.00 & $0 \frac{0}{8}$ \\
\hline & & & & & & & & & PZE-106078726 & 134.5 & 0.25 & GRMZM2G055678 & 0 & $\begin{array}{l}\text { Proline-rich receptor-like } \\
\text { protein kinase PERK1 }\end{array}$ & 0.51 & 0.34 & 0.96 & 0.99 & $0 \stackrel{\frac{2}{D}}{\frac{0}{3}}$ \\
\hline & & & & & & & & & PZE-106078990 & 134.8 & 0.24 & & 0 & & 0.50 & 0.63 & 0.07 & 0.01 & $0 \stackrel{2}{1}$ \\
\hline $\mathrm{Sg} 9$ & 6 & $\begin{array}{c}134.3 \\
-\end{array}$ & 15 & 0.16 & 0.58 & 0.41 & 0.17 & 6 & PZE-106079041 & 134.8 & 0.28 & GRMZM2G170646 & 0.6 & GDSL esterase/lipase & 0.55 & 0.44 & 0.97 & 1.00 & $0 \frac{6}{2}$ \\
\hline & & 135.3 & & & & & & & PZE-106079060 & 134.9 & 0.25 & & 0 & Probable receptor-like & 0.57 & 0.49 & 0.96 & 1.00 & 0.88 \\
\hline & & & & & & & & & PZE-106079065 & 134.9 & 0.27 & GRMZM2G162702 & 0 & protein kinase & 0.57 & 0.49 & 0.98 & 1.00 & \\
\hline & & & & & & & & & PZE-106079127 & 135.0 & 0.29 & GRMZM2G307720 & 0 & TATA box-binding protein & 0.49 & 0.31 & 0.92 & 1.00 & \\
\hline
\end{tabular}


A)

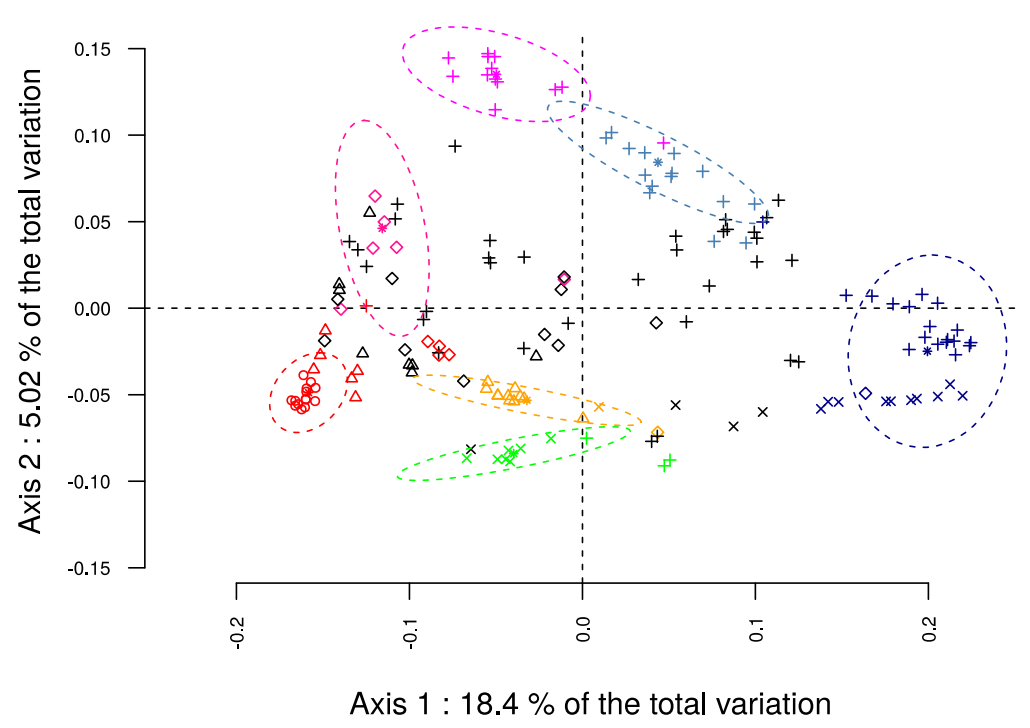

Genetic Groups

Northern Flint

Corn Belt Dent

Mexican

Andean

Caribbean

Pyrenean-Galician

Italian Flint

Admixed $(<0.6)$

Geographical Origin

$\Delta$ Central America and Mexico

+ Europe

$\times$ North America

$\diamond$ South America
B)

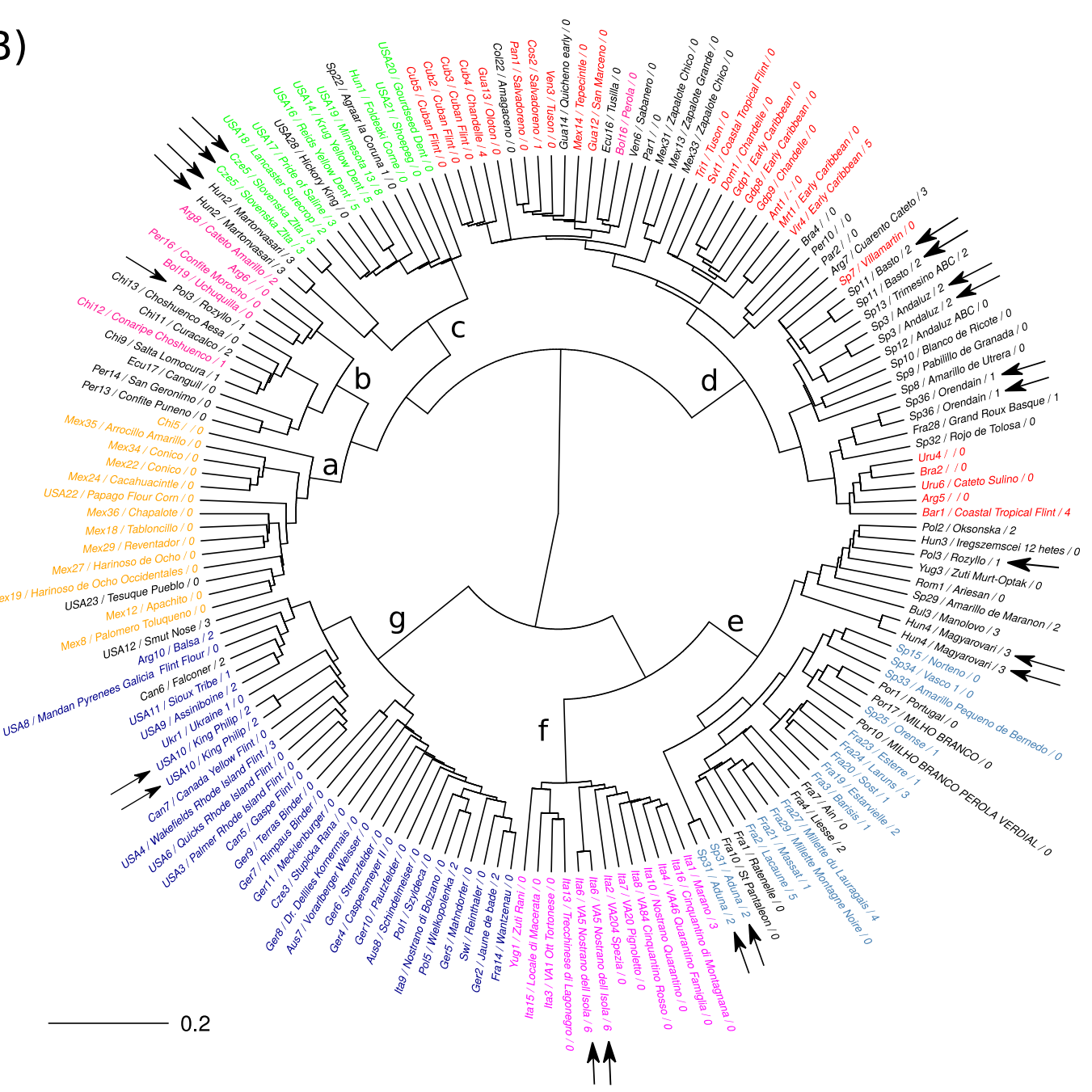

$\uparrow \uparrow$

Fig. 1: Genetic relationship between 156 maize landraces based on their modified Roger's distance (MRD). A) Projection of the 166 DNA samples on the first two axes of the Principal Coordinate Analysis. Symbols indicate the geographic origin of landraces. B) Dendrogram obtained by Hierarchical clustering, using Ward's algorithm. Labels indicate for each landrace their abbreviation code, common names and number of first cycle inbred lines they contributed to, respectively. Black arrows indicate the 10 landraces with duplicated DNA samples. Colors indicate the assignment of landraces to the seven genetic groups defined by ADMIXTURE. Landraces with an assignment probability below 0.6 were considered admixed and colored in black. 
A)

60.

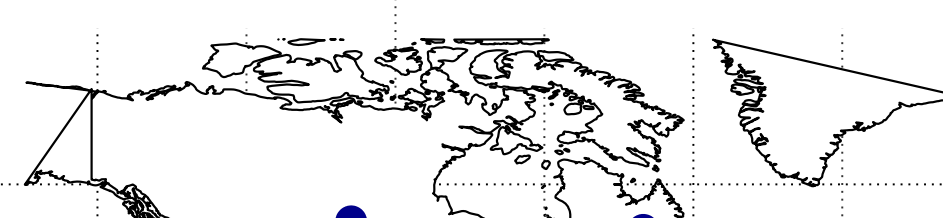

40
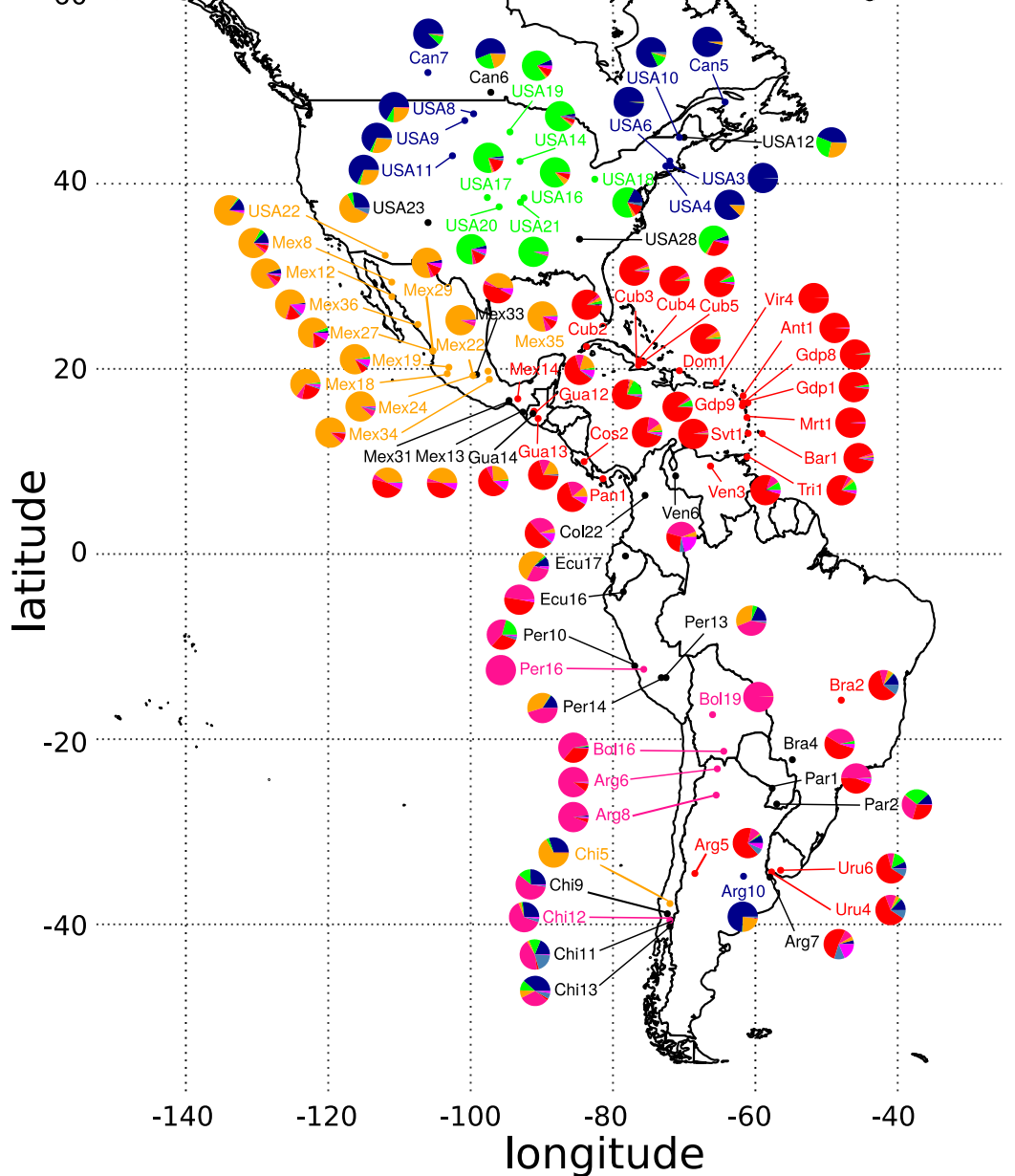

B)

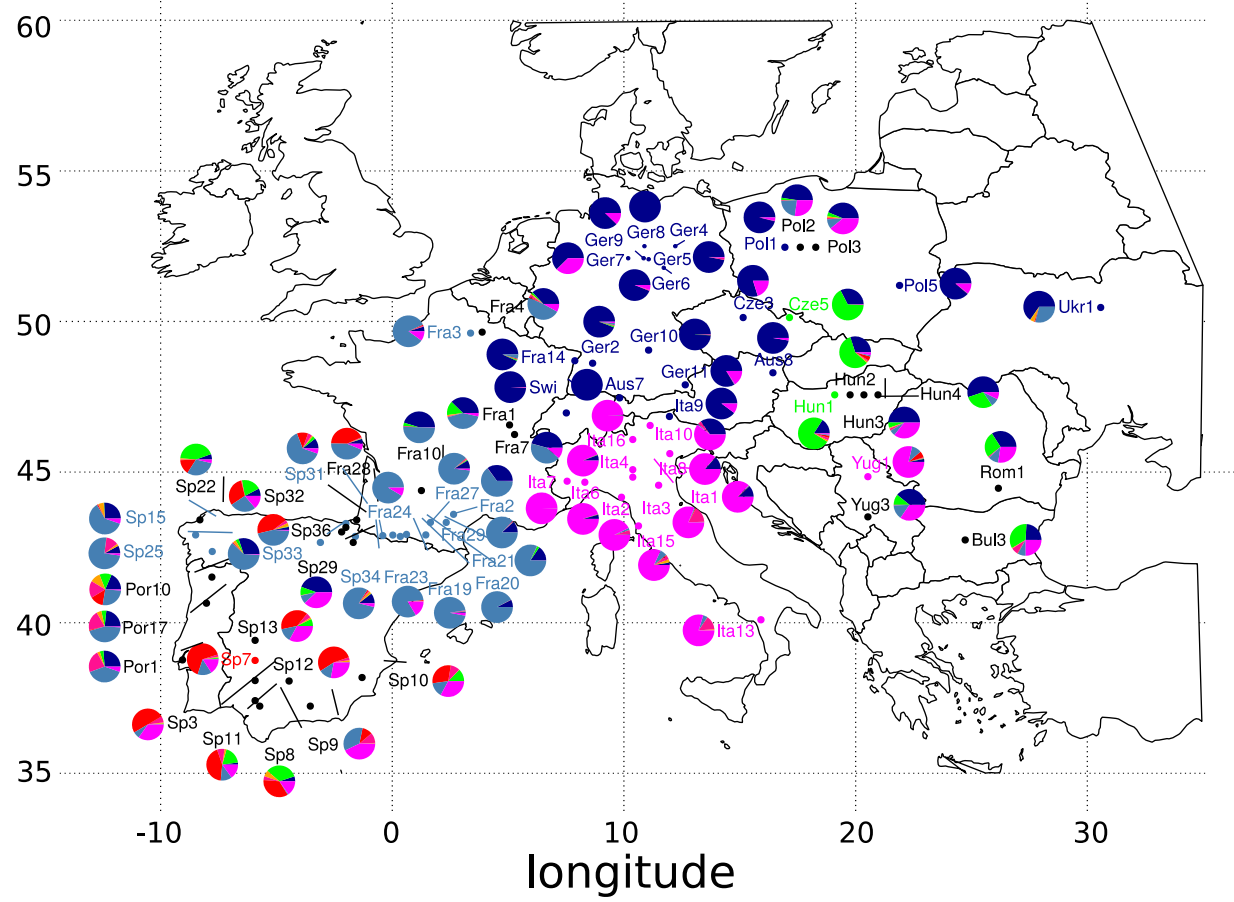

\section{Genetic Groups}

- Northern Flint

- Corn Belt Dent

- Mexican

- Andean

- Caribbean

- Pyrenean-Galician

- Italian Flint

Fig. 2: Spatial genetic structure of American (A) and European (B) maize landraces. Population structure is based on ADMIXTURE analysis with $\mathrm{K}=7$. Each population is represented by a pie diagram whose composition indicates admixture coefficients. Population labels are colored according to their main assignment (>0.6), and are black if the landrace is admixed. 
bioRxiv preprint doi: https://doi.@̊rg/10.11.01/2020.09.30.321.018. this version posted October 2, 2020. The copyright holder for this preprint

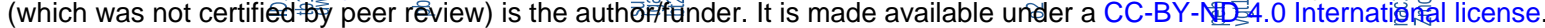

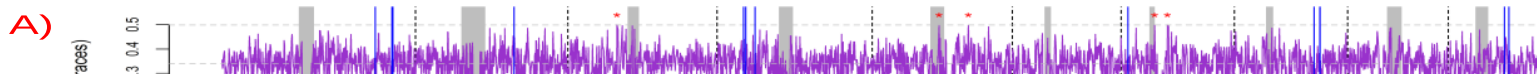

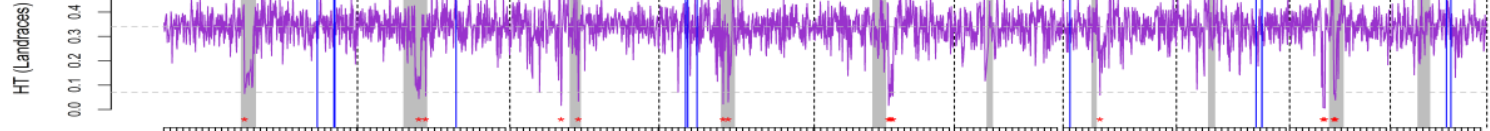

B)

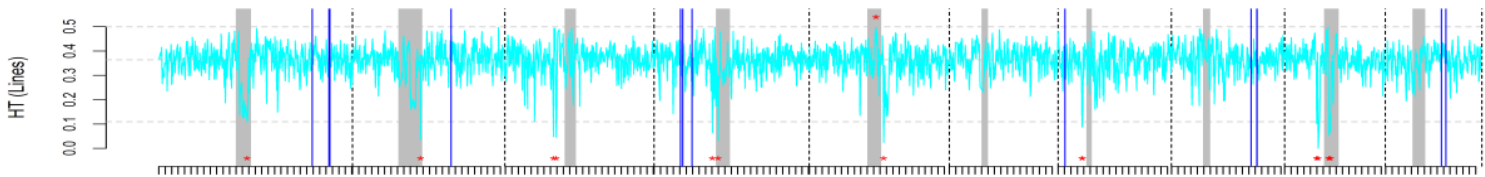

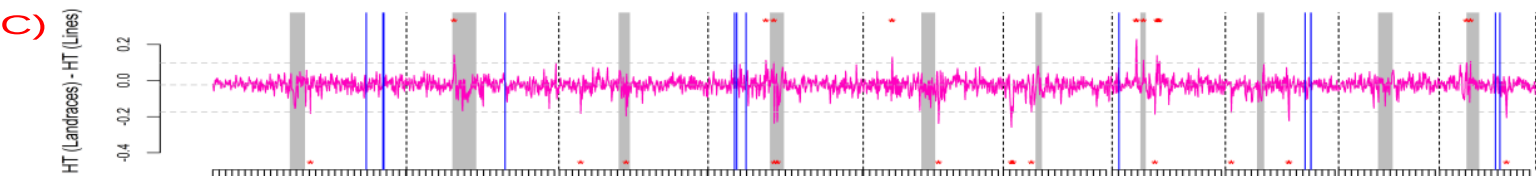

D)

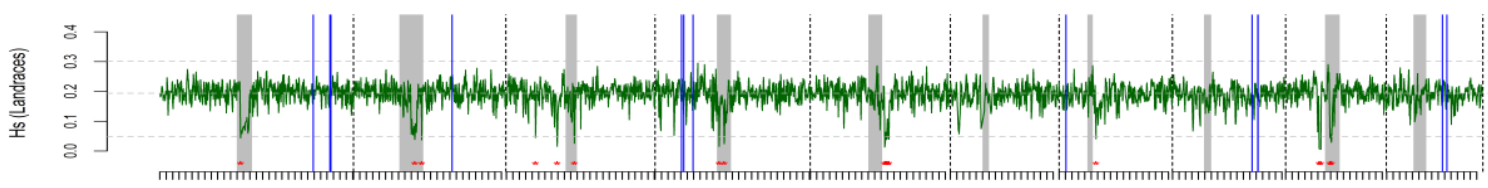

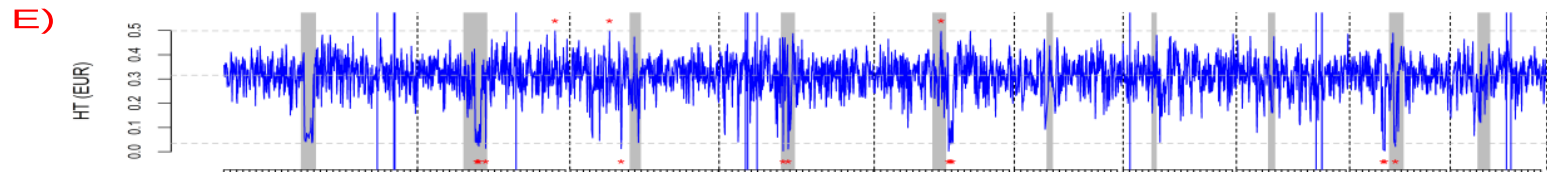

F)

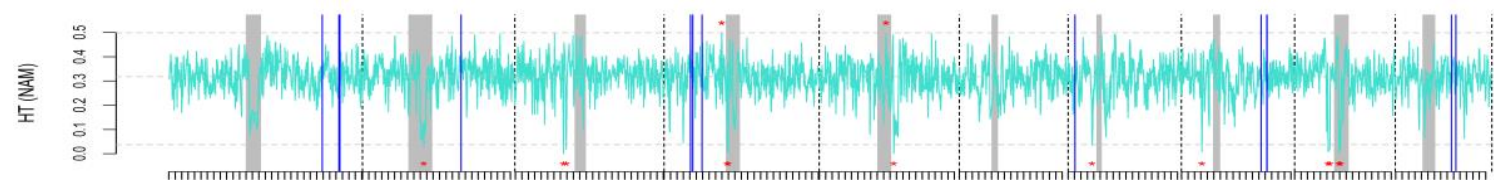

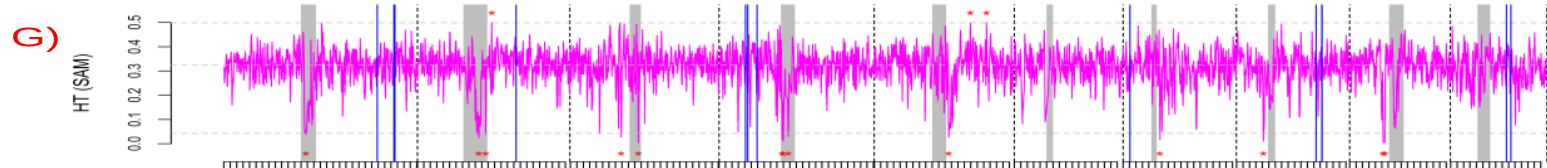

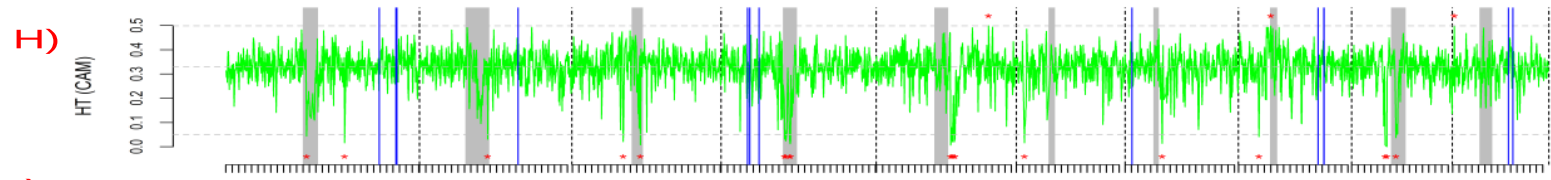

I)

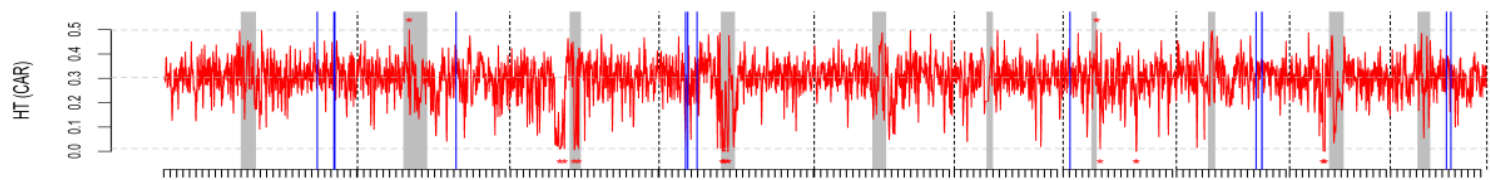

J)

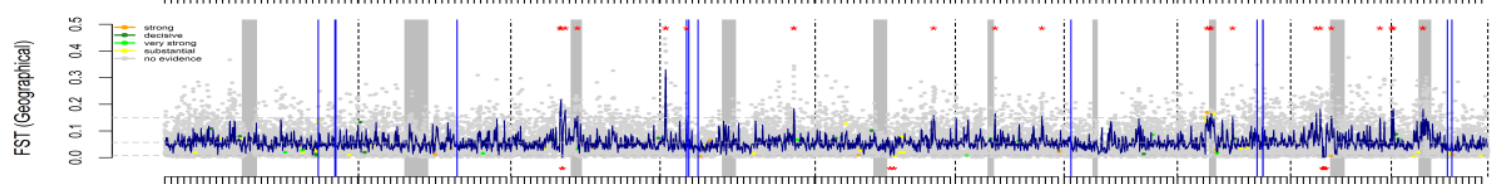

K)

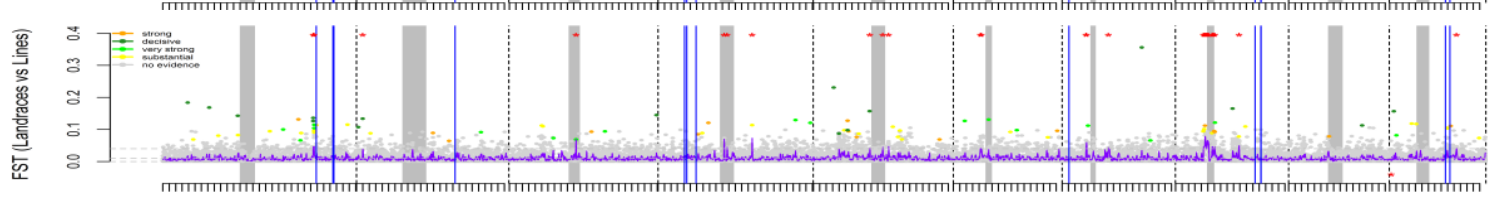

ᄂ)

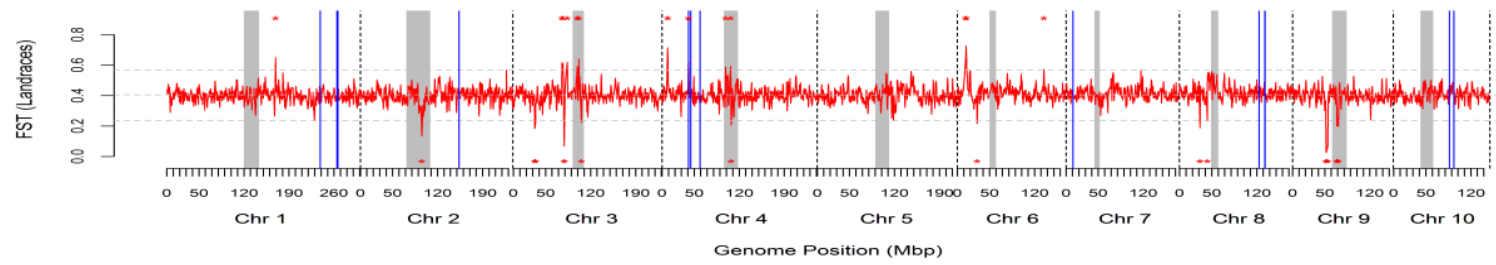


bioRxiv preprint doi: https://doi.org/10.1101/2020.09.30.321018. this version posted October 2, 2020. The copyright holder for this preprint (which was not certified by peer review) is the author/funder. It is made available under a CC-BY-ND 4.0 International license.

Fig. 3: Variation in genetic diversity and differentiation along the maize genome. A) Total expected heterozygosity across landraces: HT (Landraces); B) total expected heterozygosity (HT) across inbred lines: HT (Lines); C) difference between the total expected heterozygosity across landraces and across inbred lines: HT (Landraces) - HT (Lines); D) mean expected heterozygosity within landraces: Hs (Landraces); total expected heterozygosity across landraces from E) Europe: HT (EUR)), F) North America: HT (NAM), G) South America: HT (SAM); H) Central America and Mexico: HT (CAM), I) the Caribbean: HT (CAR), J) FST between geographic groups of landraces: FST (Geographic); K) FST between landraces and inbred lines: FST (Landraces vs. Inbred lines); L) FST between landraces: FST (Landraces). Loci with decisive, very strong, strong, substantial, no evidence of selection using bayescan are colored in orange, dark green, light green, yellow and blue ( $, \mathrm{K}, \mathrm{L})$. Vertical gray bars correspond to centromere limits. Chromosome boundaries are indicated by vertical dashed lines. Horizontal dashed lines correspond to the mean, $5^{\text {th }}$ and $95^{\text {th }}$ percentile of each parameter. Outlier regions are indicated by red asterisks ( $>95 \%$ at the top, $<5 \%$ at the bottom). Vertical blue lines indicate the location of the genes ID1, tb1, pbf1, sul, tgal, bt2, o2, pebp8, vgt1, nacl and Zmcc 
A)

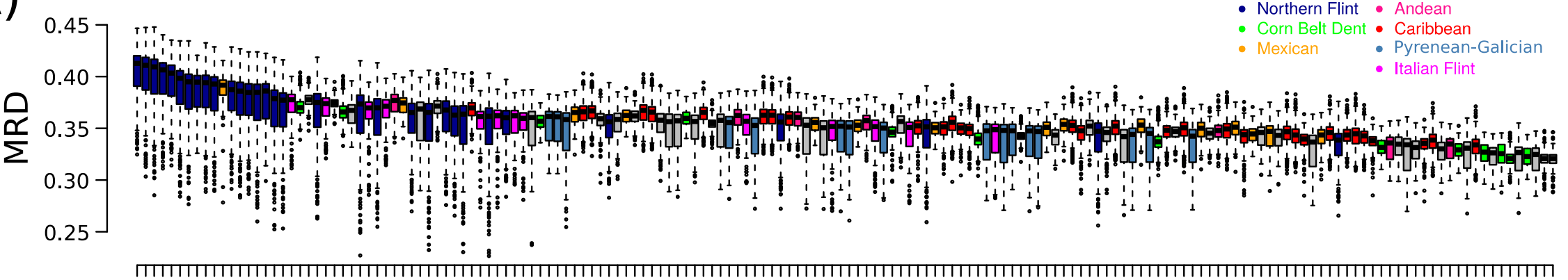

B)

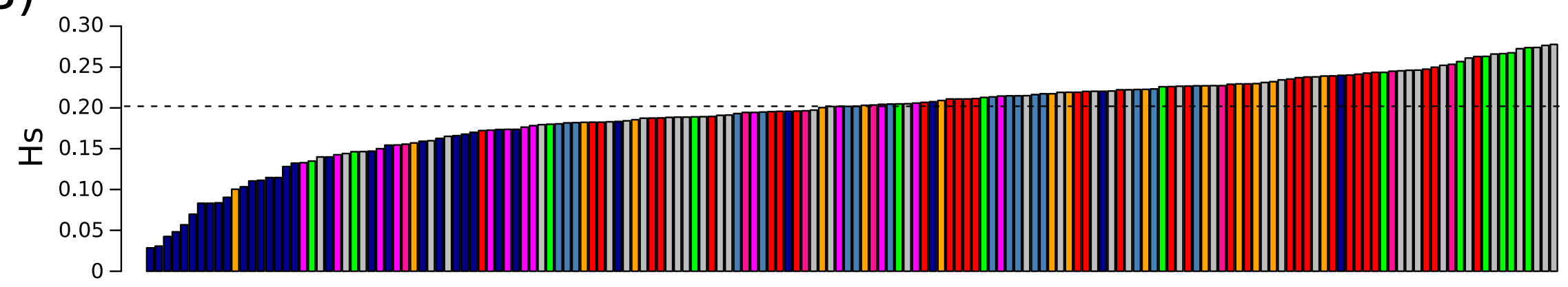

C)

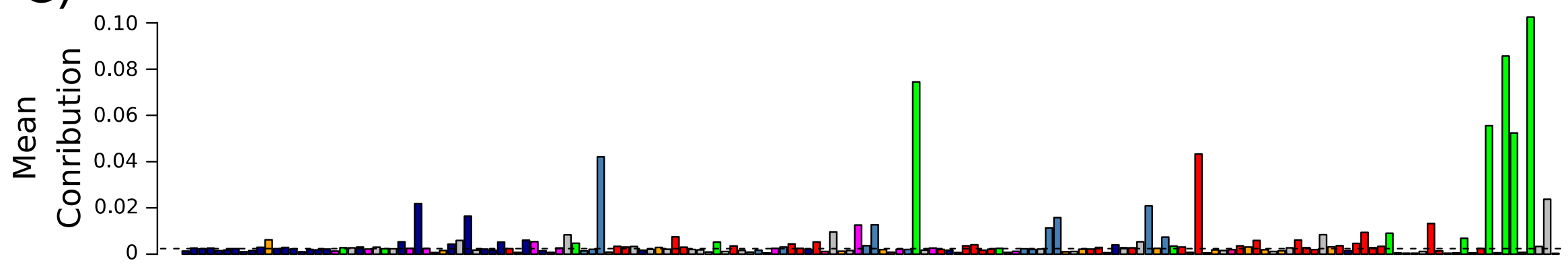

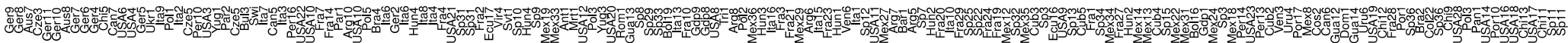

Fig. 4: Contribution of landraces to the panel of CK lines in relation to their genetic diversity. A) Box plot representation of pairwise modified Roger's distances (MRD) between individual landraces and inbred CK lines. Each box represents the interquartile range, the line within each box represents the median value and the error bars encompass 95\% of values for each landrace. Circles represent outliers. B) Within population genetic diversity (Hs) C) Average contribution of the 166 landraces to the panel of CK lines estimated by supervised analysis with ADMIXTURE. Landraces are ranked in ascending order of Hs in the three figures. Boxplot and barplots are colored based on the assignment of landraces to the seven genetic groups identified by ADMIXTURE (see bottom right for colors). 


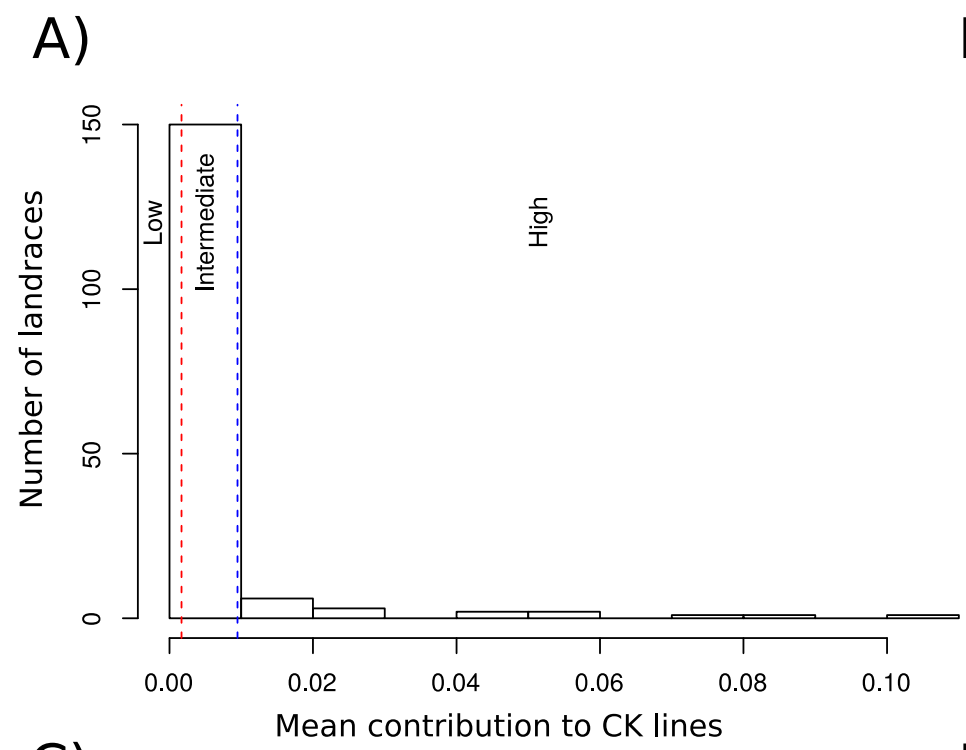

B)

C)

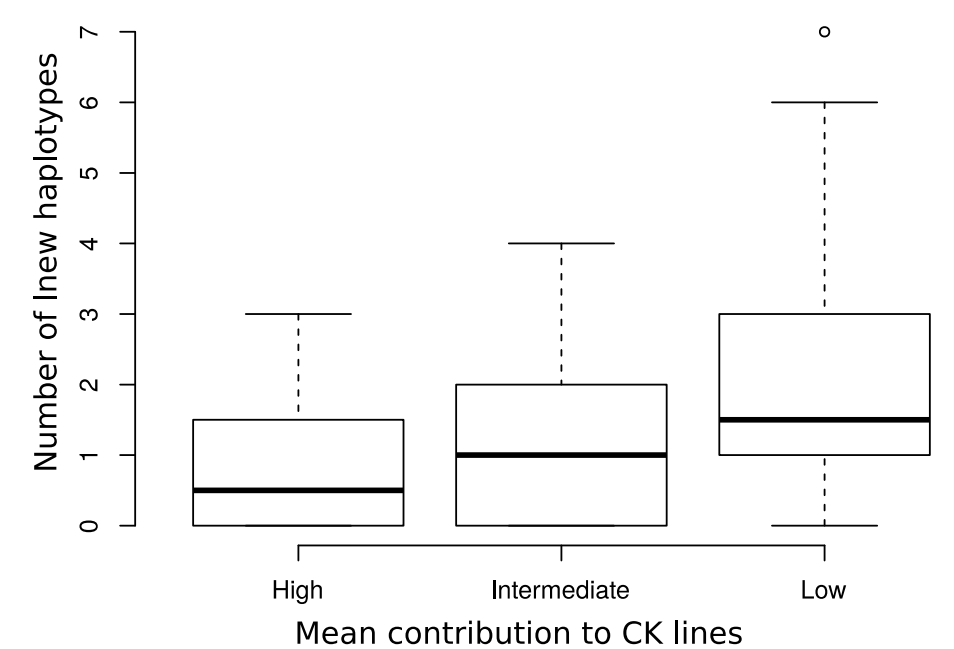

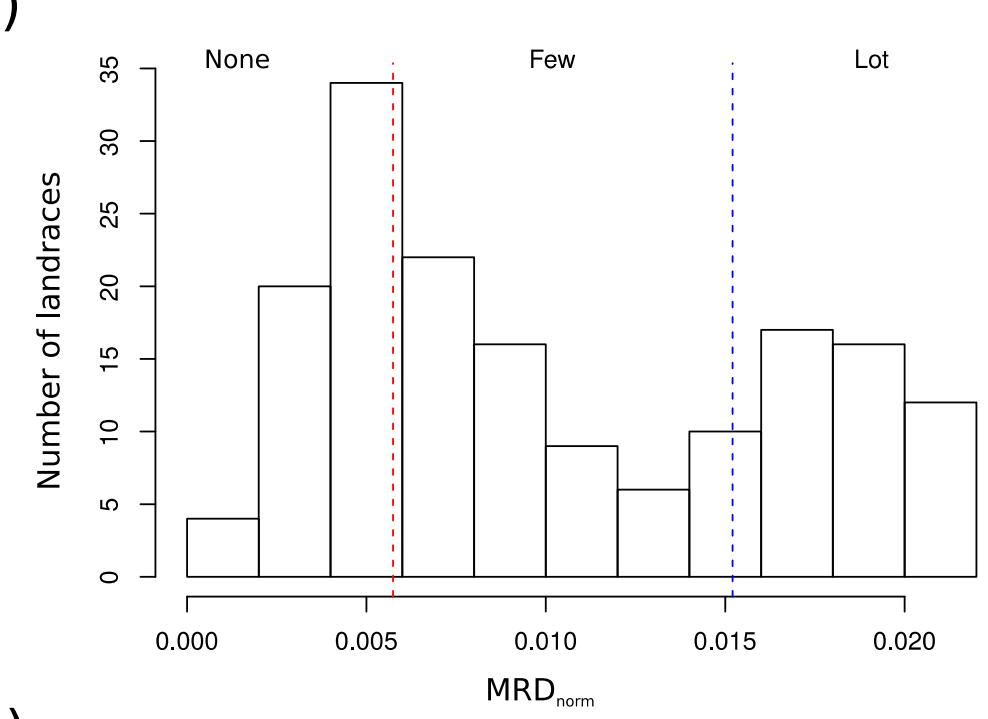

D)

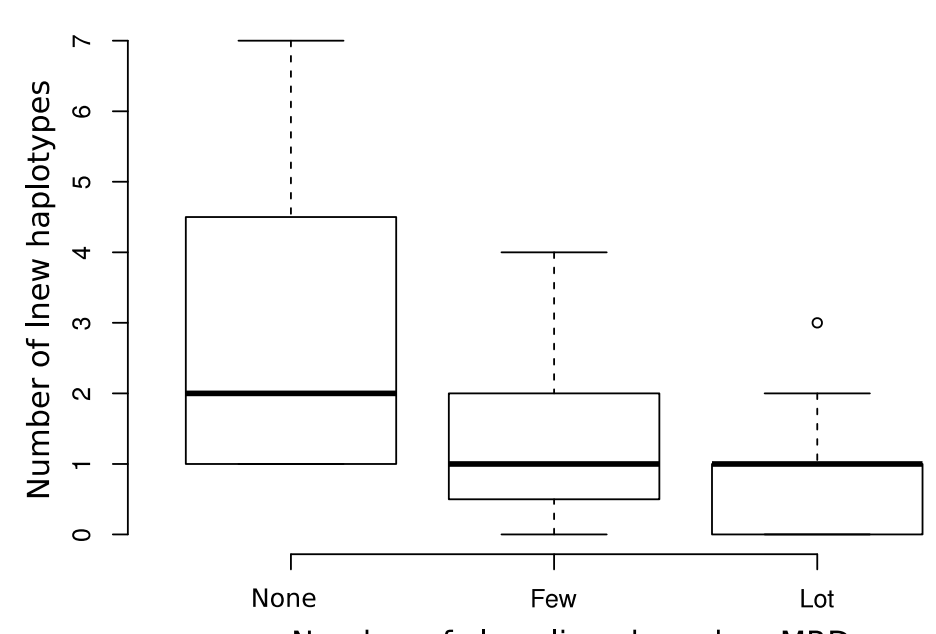

Number of close lines based on MRD ${ }_{\text {norm }}$

Fig. 5: Allelic enrichment of CK lines by new DH-SSD lines derived from landraces according their contribution and their genetic distance to CK lines. Allelic enrichment was estimated by the number of new haplotypes discovered in the 66 new DH-SSD lines derived from 33 landraces, compared to the 327 CK lines $(C, D)$ that are classified in 3 classes according to the distribution of A) the average contribution to CK line panel using supervised analysis and B) the normalized MRD (MRD $\left.{ }_{n o r m}\right)$ of the $10 \%$ closest $C K$ lines with each landrace. Red and lue vertical dotted lines delineate the limits of three landrace classes displaying A) low, intermediate and high contribution; B) the presence of none, few and many closely related lines based on MRD ${ }_{n o r m}$. 